\title{
Stability assessment of marble statuaries of the Schlossbrücke (Berlin, Germany) based on rock strength measurements and ultrasonic wave velocities
}

\author{
J. Ruedrich • C. Knell $\cdot$ J. Enseleit . \\ Y. Rieffel $\cdot$ S. Siegesmund
}

Received: 22 November 2012/ Accepted: 11 January 2013/Published online: 7 February 2013

(C) The Author(s) 2013. This article is published with open access at Springerlink.com

\begin{abstract}
The degree of weathering in natural stones on buildings and sculptures has been determined for many years in numerous cases by means of ultrasonic measurements. Conclusions concerning the strength of the rock and the type of weathering can thus be drawn. This relationship has not been established for all rock types. Most of the progress utilizing this method has been made in the analysis of marbles, where an increasing degree of weathering shows lower ultrasonic velocities. In the present study, four Carrara marble samples showing similar rock fabrics, but with respect to weathering exhibit considerable differences are investigated. Porosity varies between 0.2 vol. $\%$ and ca. 2.4 vol. $\%$, whereby with increasing porosity the pore radii changes as well. Parallel to this the ultrasonic velocities change in dry samples from about 5.5 to $1.6 \mathrm{~km} / \mathrm{s}$, respectively. Model calculations reveal that the velocity reduction is caused by cracks with an extremely small aspect ratio of about 0.005 or even less. After a specific loss of strength, however, solution processes can become active, which modify the microcracks and generate an opposite trend. In the process a strong porosity increase correlates to a relatively small velocity reduction. With the presence of water the $V_{\mathrm{p}}$ porosity weathering relationship
\end{abstract}

J. Ruedrich · C. Knell · S. Siegesmund $(\bowtie)$

Göttinger Zentrum Geowissenschaften, University of Göttingen, Goldschmidtstr. 3, 37077 Göttingen, Germany

e-mail: ssieges@gwdg.de

J. Enseleit

GSE Ingenieur-Gesellschaft mbH Saar, Enseleit und Partner,

Von-der-Gablentz-Str. 19, 13403 Berlin, Germany

Y. Rieffel

Landesdenkmalamt Berlin, Klosterstr. 47, 10179 Berlin, Germany experiences a considerable modification. Parallel to the reduction of the ultrasonic velocities, it was determined that the mechanical strength (compressive strength, flexural strength, etc.) as well as the static Young's modulus is reduced almost equally by a progressive advancement of the weathering front. In one case study dealing with tensile strengths, it was clearly documented how tensile cracks develop and propagate in dependence of the rock fabric. The rock mechanical and ultrasonic velocity data were used for stability assessments applied to the marble statuaries from the Schlossbrücke in Berlin. Stability assessments of the sculpture group 4 reveal that some critical parts must be replaced due to safety reasons.

Keywords Marble waethering - Mechanical properties . Ultrasonic wave velocites - Stability assessment . Cultural heritage

\section{Introduction}

Significant artworks have been constructed from marble in antiquity and present historical times. The "Schlossbrücke" in Berlin with its monumental sculptural groups made of Carrara marble is situated in the center of Berlin on the rim of the Museum Island, an UNESCO world cultural heritage site (Fig. 1). The sculptures now show considerable signs of damage. These examples and many others documented elsewhere have shown that the utilization of marble as a building stone can be problematic. Marble is known for its ability of undergoing a complete destruction of the fabric over time. On the other hand, thin marble plates are increasingly used as facade stones instead of solid blocks. These plates tend to bend inelastically leading to destruction within a short period of time (see 
discussion in Siegesmund et al. 2007; Logan et al. 1993; Royer-Carfagni 1999; Jornet and Rück 2000).

In the last several decades, measurements of the ultrasonic velocities have achieved more and more acceptance as a tool for analyzing the damage of marbles (Figs. 2, 3). The advantage of this method is the more or less non- destructive practicability, which is indispensable for the analysis of irrecoverable cultural heritage. The basic principle is that a progressive crack growth or crack opening during weathering leads to a decrease of ultrasonic wave velocities. For in situ measurements the compressive wave velocities is the preferred method used. Based on numerous
Fig. 1 Schlossbrücke, Unter den Linden/Berlin (all statuaries are given on two photographs $\mathbf{a}$ and b)
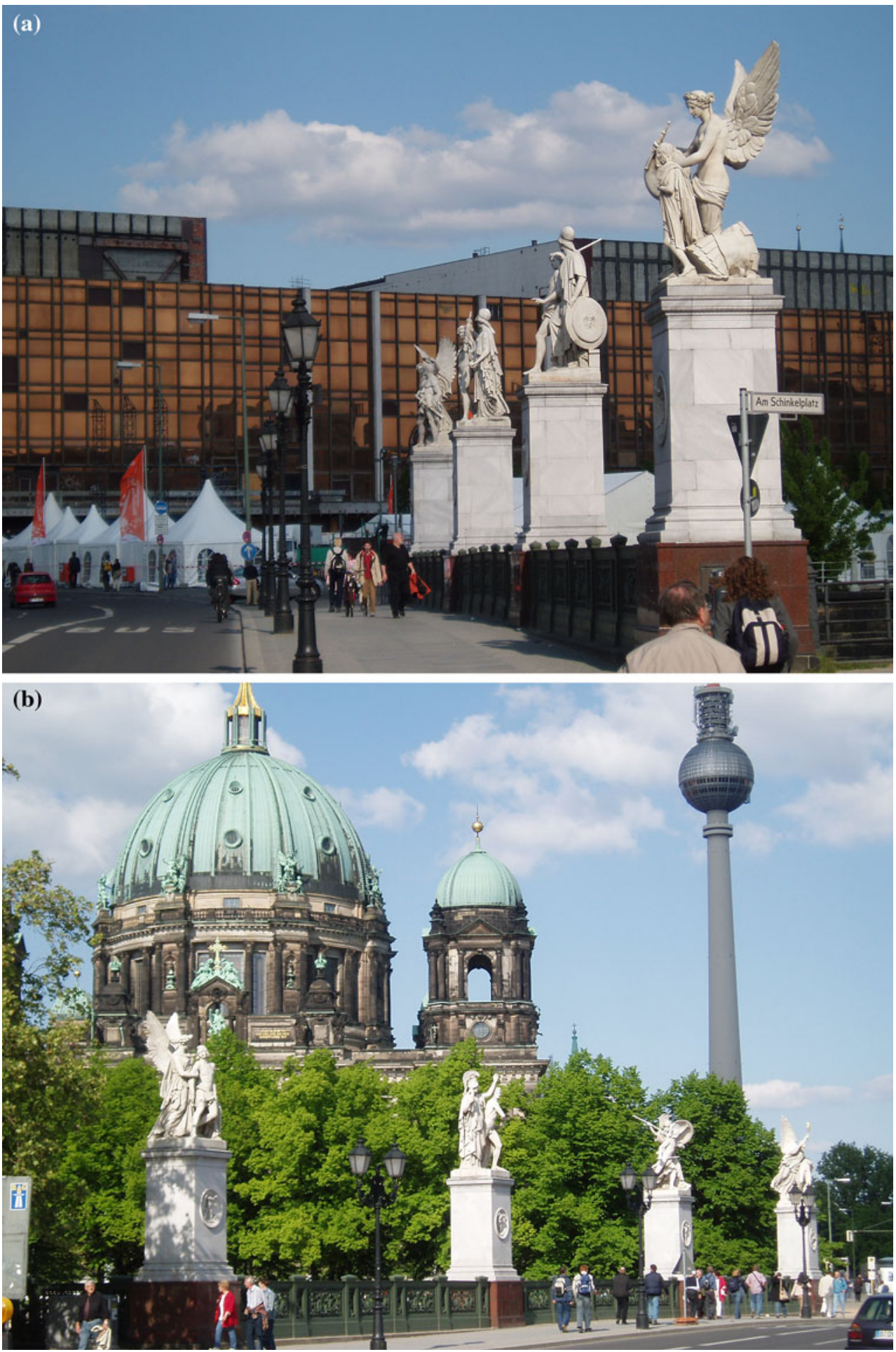
Fig. 2 Ultrasonic analysis on monuments revealed by transmission measurements on the sculpture "Nike educates the boy in history", Unter den Linden, Berlin, Germany (dots refer to a vertical ray path, while arrows characterize a diagonal ray path)
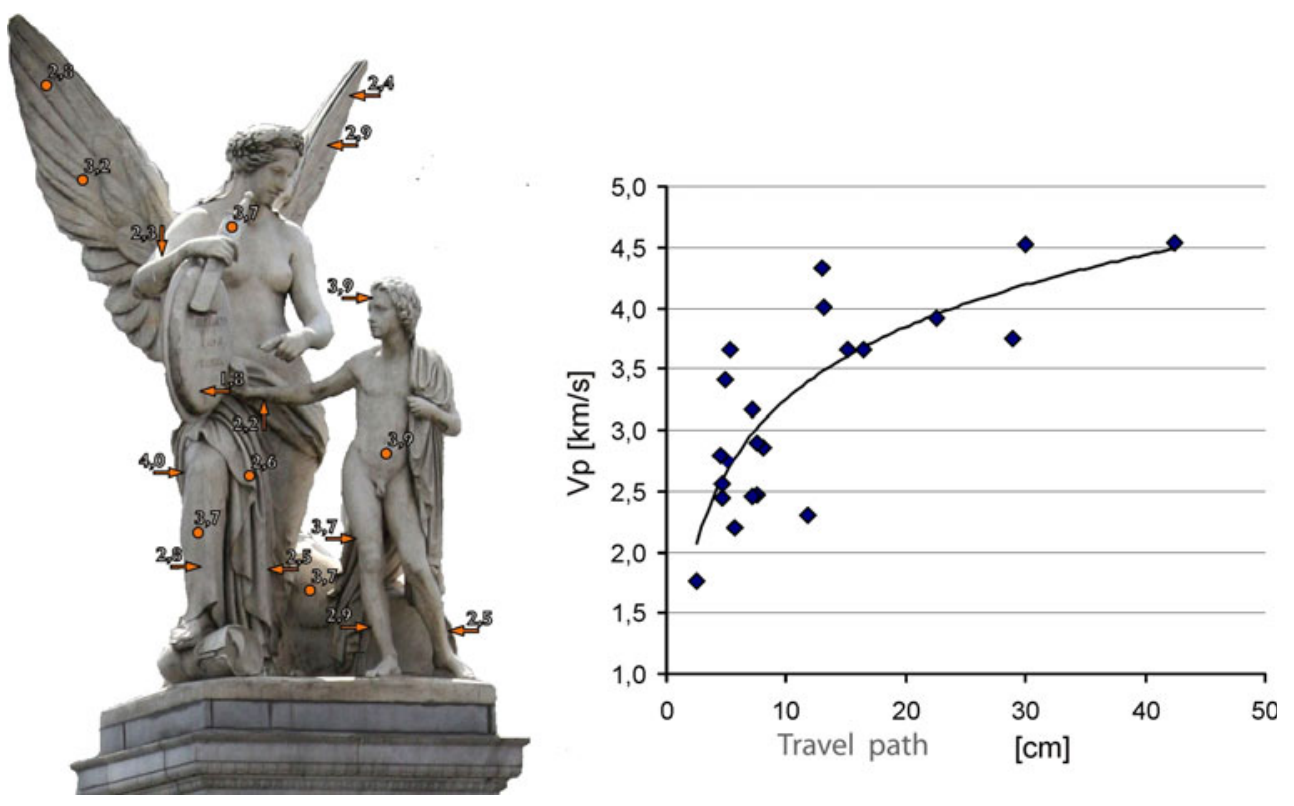

Fig. 3 Tomographic reproduction for evaluating local $V_{\mathrm{p}}$ intensities on three slices of the Sculpture group "Athena arms the warrior" $(\mathbf{a}-\mathbf{g})$

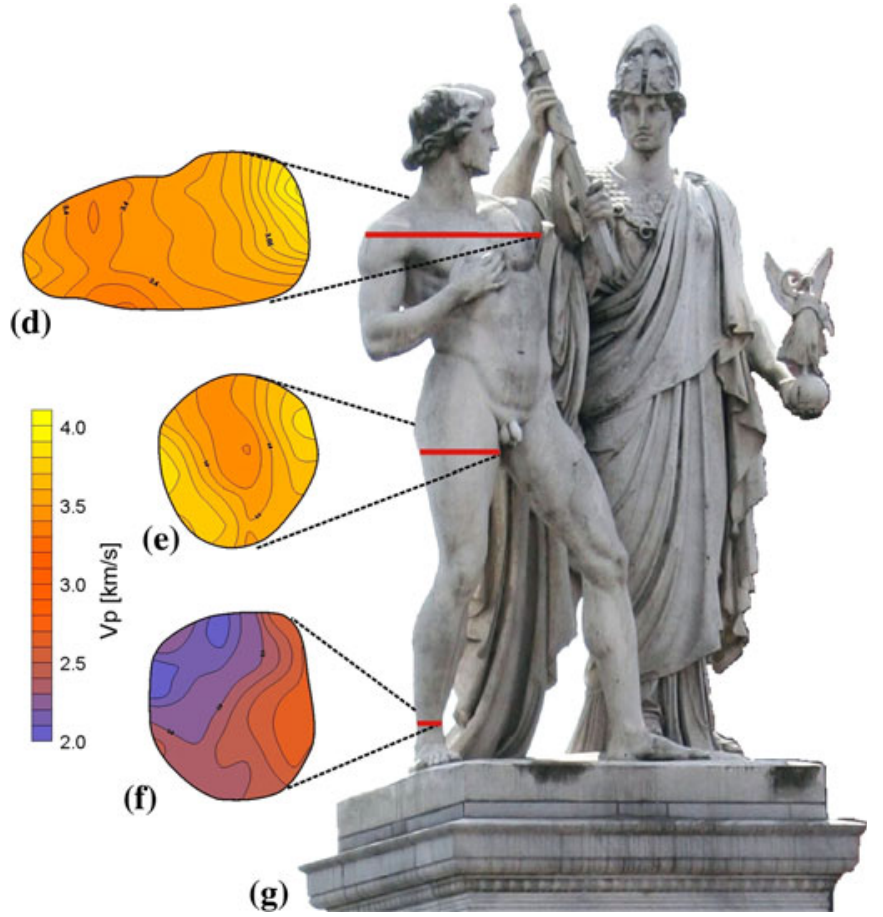

investigation to characterize the stone material. Generally, the conservation consists of closing the fractures and possibly to a large degree restoring the strength properties of the natural stone.

The aim of the present work was to obtain information concerning the connection between changes in the pore space, strength decrease, and the decrease of ultrasonic velocities during the progressive decay of marbles. For this study samples of Carrara marble in four different states of preservation were chosen: (i) fresh, (ii) slight, (iii) medium, 
Table 1 Damage classification based on $V_{\mathrm{p}}$ values of marbles (from Köhler 1991)

\begin{tabular}{llll}
\hline $\begin{array}{l}\text { Damage } \\
\text { class }\end{array}$ & $V_{\mathrm{p}}(\mathrm{km} / \mathrm{s})$ & State of preservation & $\begin{array}{l}\text { Porosity } \\
(\text { vol. \%) }\end{array}$ \\
\hline 0 & $>5.0$ & Fresh & $<0.5$ \\
I & $3.0-5.0$ & Increasing porosity & $1.3-0.5$ \\
II & $2.0-3.0$ & Crumbling surface & $3.0-1.3$ \\
III & $1.5-2.0$ & Fractured & $5.3-3.0$ \\
IV & $<1.5$ & Disintegrated & $>5 \%$ \\
\hline
\end{tabular}

and (iv) strongly weathered. The samples show a more or less comparable microfabric. This is evident by a median grain size between 160 and $180 \mu \mathrm{m}$ as well as a comparable grain fabric, which can be described as equigranular polygonal (Passchier and Trouw 1996).

In order to constrain the state of weathering, the compressional wave velocities, the tensile strength, and the uniaxial compressive strength for all investigated rocks were determined. For the correlation with the increase in porosity and the change of the pore size distribution, mercury porosimetry and hydrostatic weighting have also been carried out. The information on the decrease in strength can aid in evaluating the structural integrity of sculptures and facades made of Carrara marble. Furthermore, the mechanical data were also used for ongoing stability assessments of the statuaries from the castle bridge.

\section{Historical background}

The Schlossbrücke was constructed between 1822 and 1824 in the classical style according to a design by Karl Friedrich Schinkel. Artistically, this is the most beautiful bridge in the city of Berlin (Fig. 1). It was completed in the period from 1842 to 1857 and consists of eight groups of figures constructed of Carrara marble by sculptors of the Schadow and Rauch School. These sculptures, such as the Goddesses of Antiquity (Nike and Athena) with young heroes were also a part of the design plans of Schinkel. High pedestals of red granite were constructed on the stone pillars of the bridge and serve as the base for the largerthan-life sculptures. The ensemble of bridge figures made of Carrara marble is reminiscent of the Angels Bridge in Rome and is one of the outstanding examples of the world famous Berlin sculptural school of the nineteenth century. The bridge, with its monumental groups of figures, is a major element of the sculptural program designed by Schinkel and Rauch. Today they line up along a busy inner city street, which is a major traffic artery and forms a part of the buffer zone around the Museum Island. This circumstance, i.e. the location of the bridge in the center of the city and the fact that it has been in the public focus since it was built, is the main reason why the sculpted figures in particular have experienced a turbulent history and a variety of restoration phases.

Directly after the sculptures were assembled in 1855 and 1860 , they were treated with a coating of soluble glass as a preventive measure against air pollution. For the same reason, the figures were treated with an emulsion wash roughly every 3 years until 1916. Up to 1943 no further work on the figures is documented, and a comparison of historical photographs shows that regular cleaning and care of the statues was no longer carried out. The condition of the figures deteriorated progressively, and in some places they were distinctly blackened. In 1943 the sculptures were disassembled to protect them from war damage, and they were stored in wooden coverings at various locations in the western part of the city. The poor storage conditions up to 1969 led to a drastic deterioration in the condition of the sculptures, with parts broken off. At the end of the 1960s the sculptures were reassembled again and the missing parts were replaced. From 1978 they were stored in a "lapidarium". After the sculptures were returned from West Berlin to the GDR in 1981, they were cleaned, reinforced with silicone resin and treated hydrophobically. In 1983/84 they had been erected at the original location. During a restoration work in 1992/93, the silicone resin coating was removed abrasively by microblasting. In 2007 , a careful restoration program began, which is based on a minimal intervention concept.

\section{Rocks investigated}

For the investigation of the strength properties and its cross correlation to ultrasonic wave velocities as a function of the state of weathering, representative Carrara marble samples were collected (Fig. 4) representing four different preservation conditions: fresh (Cfr), slightly weathered (Csl), medium weathered (Cme), and strongly weathered (Csr). All weathered samples come from the Marble Palace in Potsdam (Germany). The samples were originally part of an Attica cornice of the palace's south wing. The marble samples were produced during the time of construction and were replaced during the restoration work at the end of the twentieth century. The fresh sample was taken from a quarry near Gioia in the Carrara region of Italy.

Macroscopically, the samples are characterized by a more or less comparable appearance. They show a weak and irregular dark veined metamorphic layering. A strongly oriented foliation is not observable. However, the veins show a slight preferred orientation. Between the dark veins the marbles appear milky white, which is a typical attribute of weathered Carrara marble (Fig. 4). In contrast, the fresh 
Fig. 4 Investigated samples of Carrara marble: weathered specimens from the Marble Palace in Potsdam and a fresh reference sample from the quarry near Gioia (Italy)
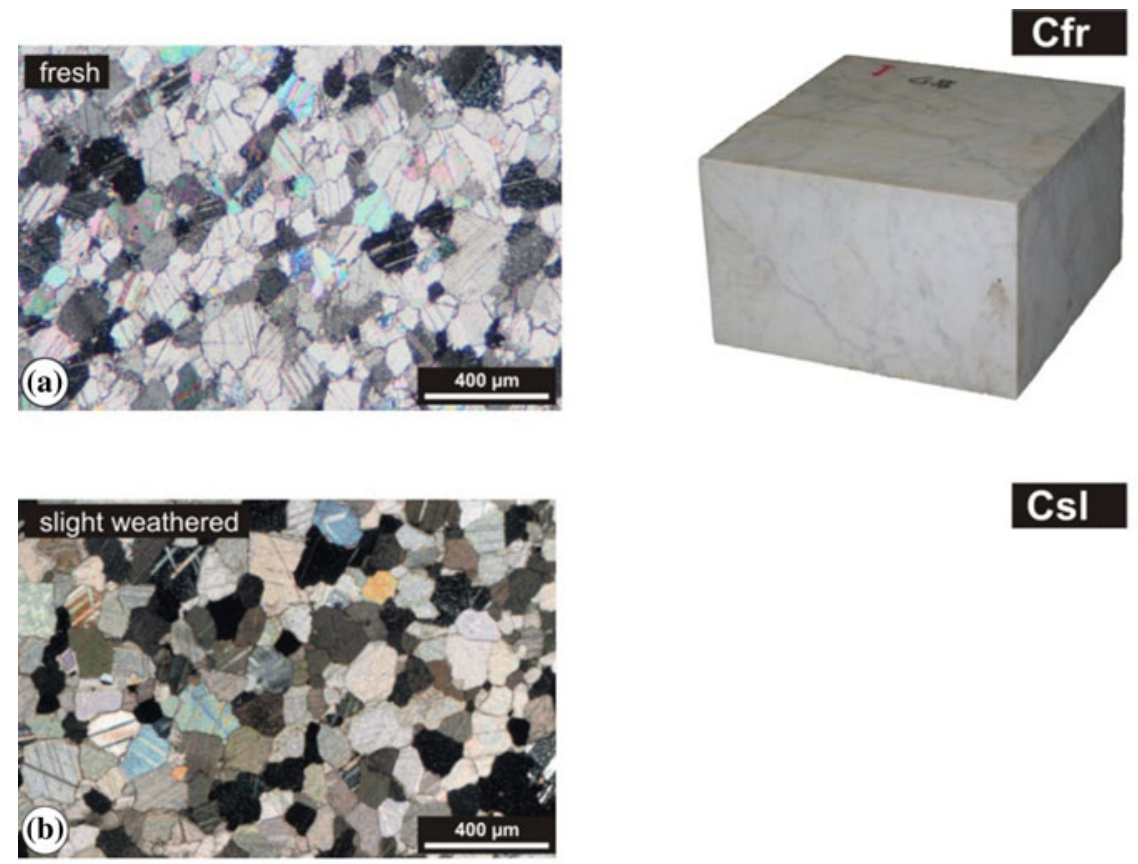

CsI
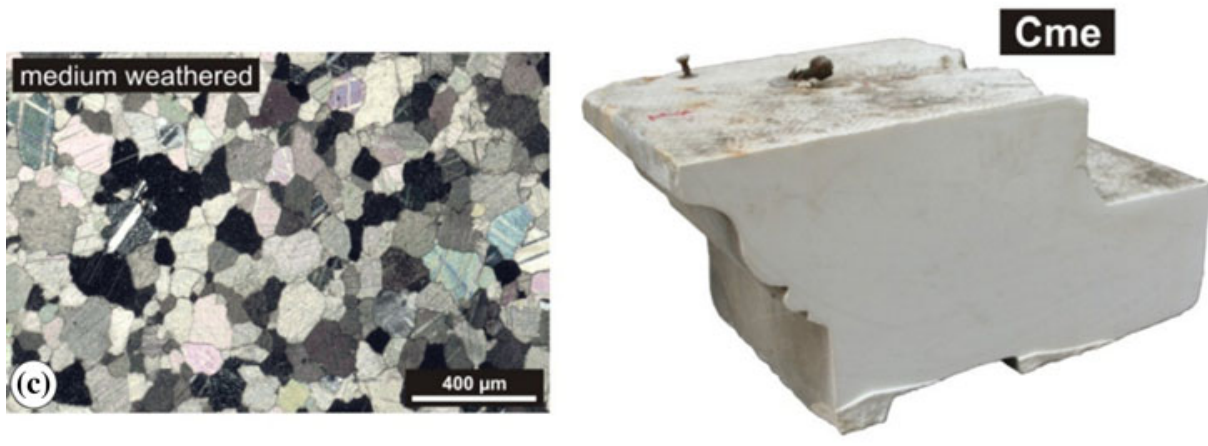

Cst
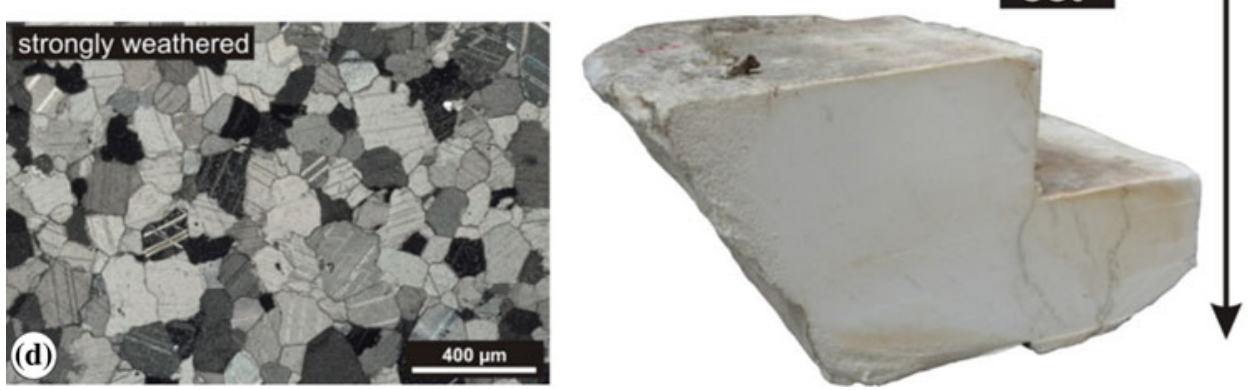

sample exhibits a grayish appearance and shows stronger veining as defined by the irregular dark layers. The different preservation states of the weathered marbles are also visible on the sample surfaces. The original surfaces of the slightly and medium weathered specimens are well preserved, whereas the strongly weathered sample shows a significant loss of the original marble surface. The damage is caused by a sugar-like crumbling of calcite grains, which leads to a straightening of the ornamentation.
The investigated marbles exhibit a medium grain size of about $180 \mu \mathrm{m}$. The samples show a more or less polygonal and equigranular grain fabric (Fig. 4). The grain boundaries are slightly curved to weakly interlocking. Often straight boundaries occur. Polysynthetic twinning of the calcite grains is rare. Cleavage planes occur frequently and are observable in the fresh sample. This may be due to mechanical deformation during the thin section preparation. 
Fig. 5 Microfabric analysis of the slightly weathered Carrara marble sample. a Grain fabric, b grain size distribution, $\mathbf{c}$ grain boundary orientation and d lattice preferred orientation of calcite crystals (texture) (a)
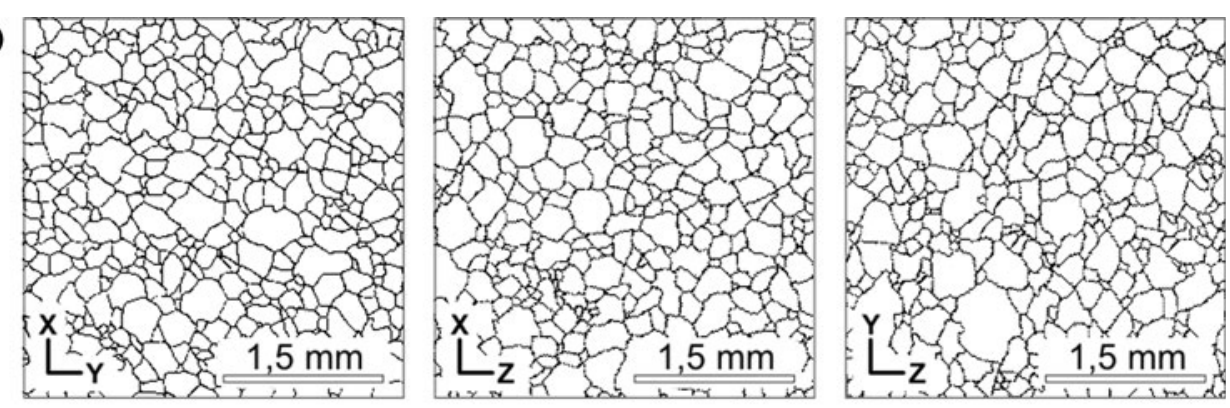

(b) 40
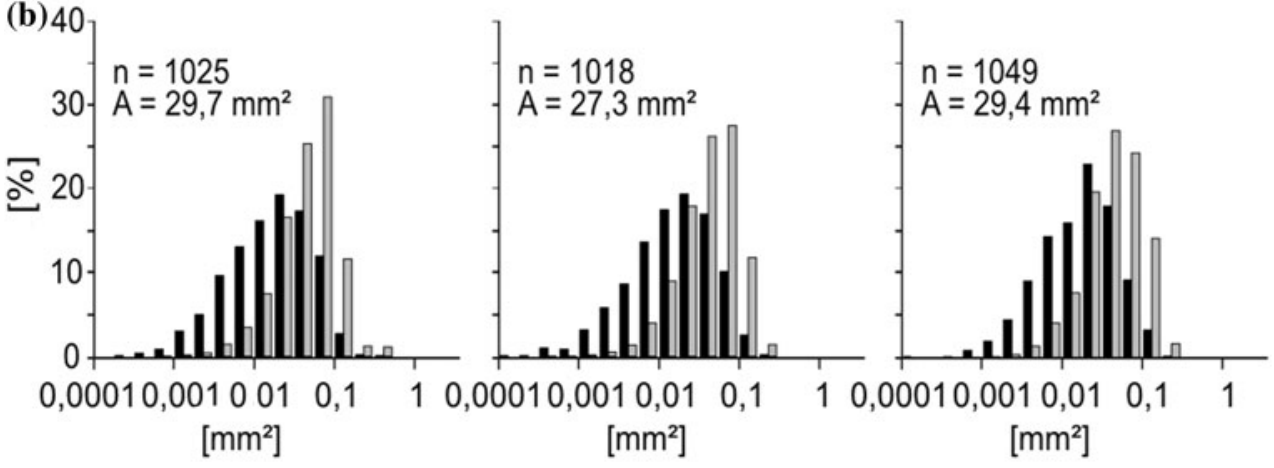

(c)
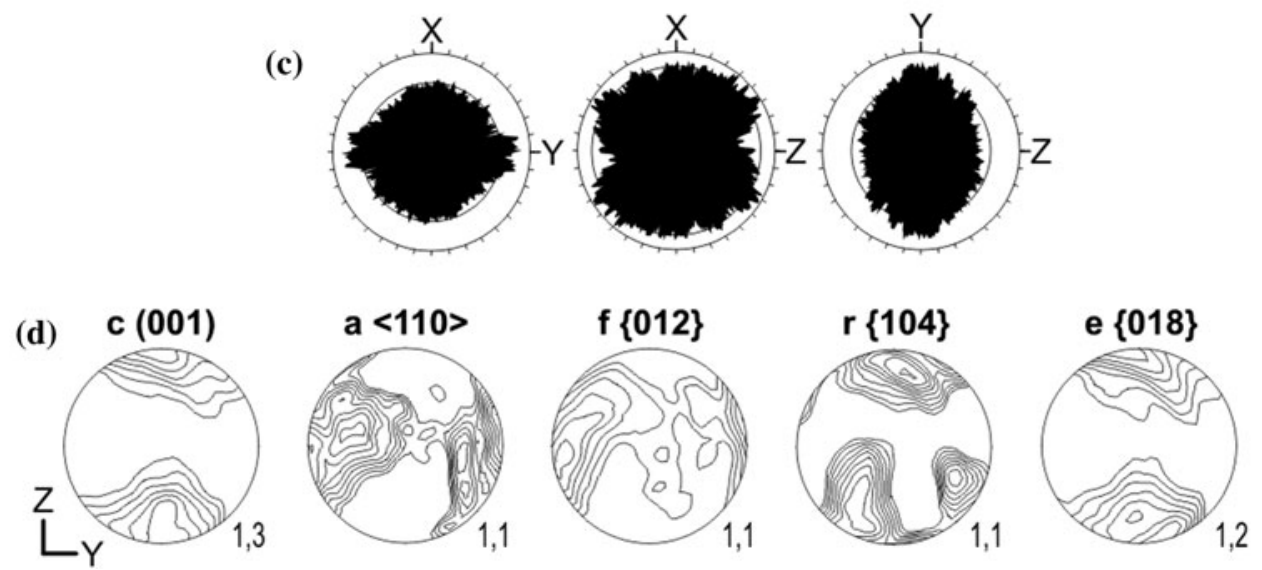

Detailed fabric investigations were done on the slightly weathered sample (Fig. 5). Image analysis was performed on three orthogonal digitized thin sections (Duyster 1991). Macroscopically, the specimen shows a bright white color and contains irregular gray veins. The veins are folded and display a streak-like distortion and usually range from 0.5 to $2 \mathrm{~cm}$ in width. A preferred orientation of the veins is not clearly detectable. The sample shows a weak decay in the form of granular disintegration.

Microstructurally, the Carrara sample shows a nearly equigranular polygonal grain fabric (Fig. 5a) with straight grain boundaries and $120^{\circ}$ triple-point junctions (Fig. 5a). The grain size is given as an average area parameter (Fig. 5a-d). The percentage of a specific area class was computed as a function of total area and total number of grains (Fig 5a). The grain size is about $200 \mu \mathrm{m}$ and the grain size distribution shows a narrow maximum (Fig. 5a). In the $X Y$ plane of the investigated sample a weak preferred grain boundary orientation (subparallel $Y$ direction) can be observed (Fig. 5a).

The lattice preferred orientation (here referred to as texture) of the marble was determined by means of neutron diffraction (Siegesmund et al. 1999; Ullemeyer et al. 2000). Due to the high penetration depth of neutrons, large sample volumes may be investigated and a better approximation of the bulk rock texture is achieved. The analyzed texture pattern of the Carrara sample can be described as $c$-axis fiber type. Correspondingly, all other plane normals and axes form small girdle distributions around this fiber axis. The texture intensity is weak with a c-axes maximum of $1.3 \mathrm{mrd}$. This low texture is typical for Carrara marbles (Leiss and Ullemeyer 1999; Weiss et al. 1999; Ruedrich 2003). 
Fig. 6 Used reference system: a the three orthogonal directions with regard to the foliation and lineation and $\mathbf{b}$ directional sampling for flexural and compressive strength analysis with indication of the induced stresses by mechanical loading (arrows)

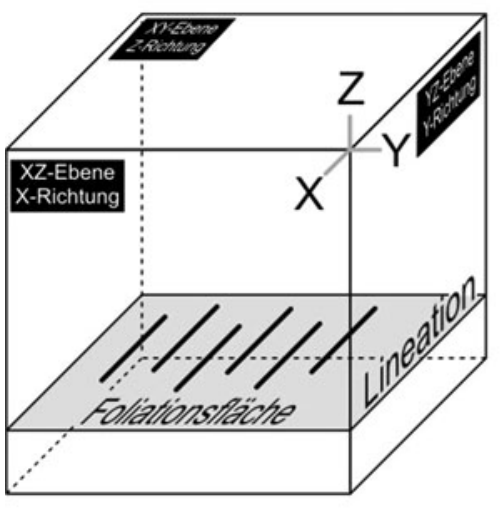

(a)

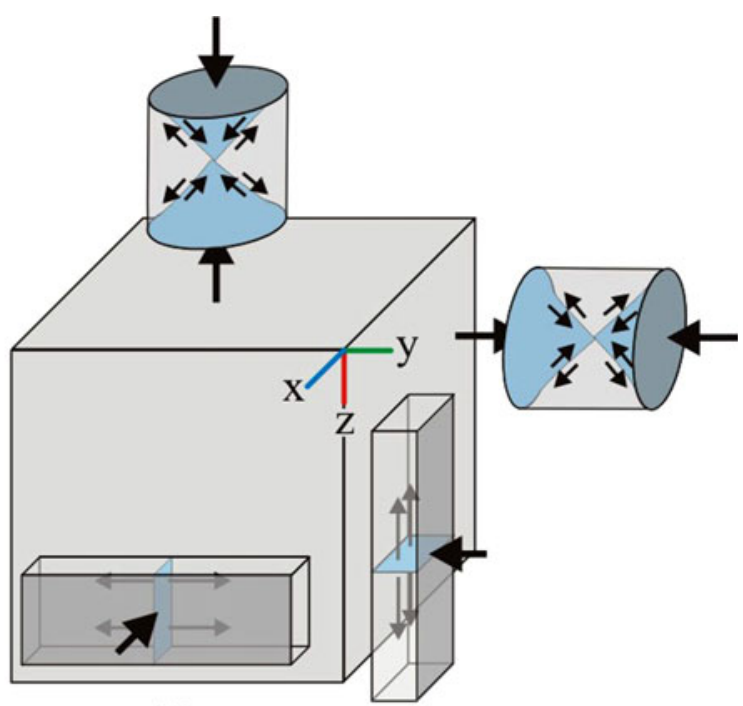

(b)

\section{Methods}

In order to take the directional dependency of the rock parameters into account, the investigations were performed on specimens from mutually perpendicular directions (Fig. 6). For this a reference coordinate system with respect to the macroscopically visible elements of foliation and lineation was chosen $(\mathrm{X}, \mathrm{Y}, \mathrm{Z})$. The $X Y$ plane delineates the metamorphic foliation.

\section{Porosity}

In order to characterize the total accessible porosity $(\Phi)$, measurements of hydrostatic weighting were performed on sample cubes $(65 \times 65 \times 65 \mathrm{~mm})$. The dry $\left(\mathrm{m}_{\mathrm{dry}}\right)$, the saturated $\left(\mathrm{m}_{\mathrm{sat}}\right)$, and the hydrostatic mass $\left(\mathrm{m}_{\text {hydro }}\right)$ of the saturated samples were determined. Total water saturation was obtained by using a vacuum. Porosity was calculated by $\Phi=\left(\left(\mathrm{m}_{\mathrm{sat}}-\mathrm{m}_{\mathrm{dry}}\right) /\left(\mathrm{m}_{\mathrm{sat}}-\mathrm{m}_{\text {hydro }}\right) \cdot 100\right)$. The porosity measurements were carried out on cylindrical samples (50 $\mathrm{mm}$ diameter, $50 \mathrm{~mm}$ length).

\section{Pore radii distribution}

The pore size distribution of the rocks was determined by using mercury porosimetry (Brakel et al. 1981). The investigations were carried out with pressures up to $2 \mathrm{kbar}$, which allows the evaluation of pore radii of about $0.005 \mu \mathrm{m}$. At least three cylindrical specimens $(\varnothing 12.5 \times 20.0 \mathrm{~mm})$ of every rock sample were analyzed. The results show comparable distributions for the respective rock. The data in Table 2 represent results of single measurements.

\section{Compressional wave velocities}

Investigations of the compressional wave velocities $\left(V_{\mathrm{p}}\right)$ were performed to obtain information about the elastic properties of the marbles. The transient times of ultrasonic pulses (piezoceramic transducers with a resonant frequency $250 \mathrm{kHz}$ ) were measured using the transmission technique (Birch 1960). To correlate the $V_{\mathrm{p}}$ values with the strength and pore space properties, the analyses were carried out on different specimens, which were cut from a larger sample block.

Table 2 Pore space properties of the investigated marble samples

\begin{tabular}{|c|c|c|c|c|c|c|c|c|}
\hline \multirow[t]{2}{*}{ Sample } & \multirow[t]{2}{*}{ Porosity } & \multirow[t]{2}{*}{ Deviation } & \multirow[t]{2}{*}{ Average pore radius } & \multicolumn{5}{|c|}{ Pore radii distribution [\%] } \\
\hline & & & & $0.001-0.01 \mu \mathrm{m}$ & $0.01-0.1 \mu \mathrm{m}$ & $0.1-1 \mu \mathrm{m}$ & $1-10 \mu \mathrm{m}$ & $>10 \mu \mathrm{m}$ \\
\hline $\mathrm{Cfr}$ & 0.23 & 0.03 & 0.028 & 27.14 & 52.54 & 20.32 & 0.00 & 0.00 \\
\hline Csl & 0.52 & 0.02 & 0.046 & 18.55 & 58.86 & 20.17 & 2.42 & 0.00 \\
\hline Cme & 1.45 & 0.52 & 0.378 & 0.00 & 6.30 & 86.12 & 7.58 & 0.00 \\
\hline Cst & 2.33 & 0.25 & 0.923 & 0.00 & 5.83 & 38.68 & 55.50 & 0.00 \\
\hline
\end{tabular}




\section{Flexural strength}

The flexural strength $\left(\sigma_{\mathrm{FS}}\right)$ was determined using prismatic samples with the dimensions $25 \times 50 \times 150 \mathrm{~mm}$. The mechanical load was applied to the centerline of the samples between two bearings with a strain rate of $30 \mathrm{~N} / \mathrm{s}$ until failure. The flexural strength was calculated after Eq. 1 from the maximum load $F_{\max }$, the distance of the bearings and the dimension of the fracture surface. The measurements have been carried out on a minimum of six samples per direction (parallel $\mathrm{X}$ and $\mathrm{Z}$ ).

$\sigma_{\mathrm{FS}}=3 * F_{\max } * \mathrm{~d} / 2 * \mathrm{w} * \mathrm{~h}^{2}[\mathrm{MPa}]$

\section{Uniaxial compressive strength and Young's modulus}

For the uniaxial compressive strength $\left(\sigma_{\mathrm{UCS}}\right)$, measurements on cylindrical specimens $(50.0 \mathrm{~mm}$ diameter, $50.0 \mathrm{~mm}$ length) with coplanar end-faces (accuracy of 0.1 per cent) were performed. The load was applied to the end-faces of the specimen with a strain rate of $1,000 \mathrm{~N} / \mathrm{s}$ until failure. The maximum load is defined as the uniaxial compressive strength (Eq. 2). The analysis was done on a minimum of six samples per direction (parallel $\mathrm{X}$ and $\mathrm{Z}$ ).

$\sigma_{\mathrm{FS}}=3 * F_{\max } * \mathrm{~d} / 2 * \mathrm{~W} * \mathrm{~h}^{2}[\mathrm{MPa}]$

The Young's modulus was determined from the stressstrain curve of the uniaxial compressive strength tests.

$\sigma_{\mathrm{FS}}=3 * F_{\max } * \mathrm{~d} / 2 * \mathrm{w} * \mathrm{~h}^{2}[\mathrm{MPa}]$

\section{Results}

\section{Pore space properties}

The fresh marble sample (Cfr) exhibits a porosity about $0.2 \%$ (Fig. 7; Table 2). This is a typical value for crystalline rocks, which in non-deteriorated preservation states show more or less no porosity (Ruedrich 2003). The slight porosity can still be produced by preparation traces at the sample surfaces. For the strongly deteriorated sample the porosity is strongly increased up to $2.3 \%$. The slightly weathered sample exhibits a porosity about $0.5 \%$ and the medium deteriorated specimen a porosity of ca. $1.5 \%$. The progressive increase of the porosity can be traced back to a progressive widening of microcracks during weathering and the connection and access to isolated microcracks.

With increasing porosity a pronounced change of the pore distribution also occurs (Table 2; Fig. 7). Generally, a more or less Gaussian distribution of the pore radius was found with one maximum and a certain amount of smaller or larger pores (unequal unimodal distribution). With progressive state of deterioration the maximum of the pore radii distribution shows a shifting to larger radii. The maximum is about $0.01 \mu \mathrm{m}$ for the fresh, about $0.10 \mu \mathrm{m}$ for the slightly weathered, between 0.10 and $1.00 \mu \mathrm{m}$ for the medium and about $1.00 \mu \mathrm{m}$ for the strongly deteriorated sample. Besides the shift of the maximum, a change in the distribution of smaller and larger pores is also observable. The fresh sample shows beside the maximum a relatively high amount of larger pores (Fig. 7a), whereas the pattern of the strongly deteriorated sample exhibits a higher number of pores, which are smaller than the maximum (Fig. 7d). In contrast, for the slight and medium weathered samples the amount of smaller and larger pores beside the maximum is nearly equal (Fig. $7 \mathrm{c}, \mathrm{d}$ ).

In Fig. 8 the average pore radius is plotted versus porosity of the respective sample. The diagram shows that the porosity increases more strongly than the pore radii. This can be explained by a change in the active weathering processes. During progressive deterioration, chemical solution processes start. Due to microcrack opening the water uptake and also drying processes increases. The chemical solution leads to a strong increase in the porosity but affect the pore radii only slightly. Furthermore, the dissolution processes might connect already existing but isolated microcracks, which have a similar pore radius.

Flexural and uniaxial compressive strength

For the investigated samples the flexural strength varies between $1.33 \mathrm{~N} / \mathrm{mm}^{2}$ for the strongly weathered and $20.22 \mathrm{~N} / \mathrm{mm}^{2}$ for the fresh marble sample. Generally, the highest values are observable by applying the tensile force parallel to the Z-direction with the exception of the medium weathered sample (Table 3). Remarkable are the extremely low flexural strength values of the strongly weathered sample. Although it is possible to prepare specimens of this sample for the measurements, the fabric cohesion against tensile forces tends to zero.

The uniaxial compressive strength exhibits values of $40.89 \mathrm{~N} / \mathrm{mm}^{2}$ for the strongly weathered and $104.52 \mathrm{~N} / \mathrm{mm}^{2}$ for the fresh sample. A plot of the uniaxial compressive strength versus the flexural strength of the investigated marbles is given in Fig. 9, whereas two noticeable features are observable. On the one hand, the flexural strength shows a strong decrease with respect to the state of weathering, while the compressive strength is less sensitive. This can be traced back to the importance of microcracks for the tensile strength (Peck et al. 1985; Brosch et al. 2000).

Elastic properties

To classify the preservation state of the investigated marble samples by ultrasound initial measurements were made 
Fig. 7 Pore radius distributions of the investigated samples a Cfr, b Csl, $\mathbf{c}$ Cme, $\mathbf{d}$ Cst
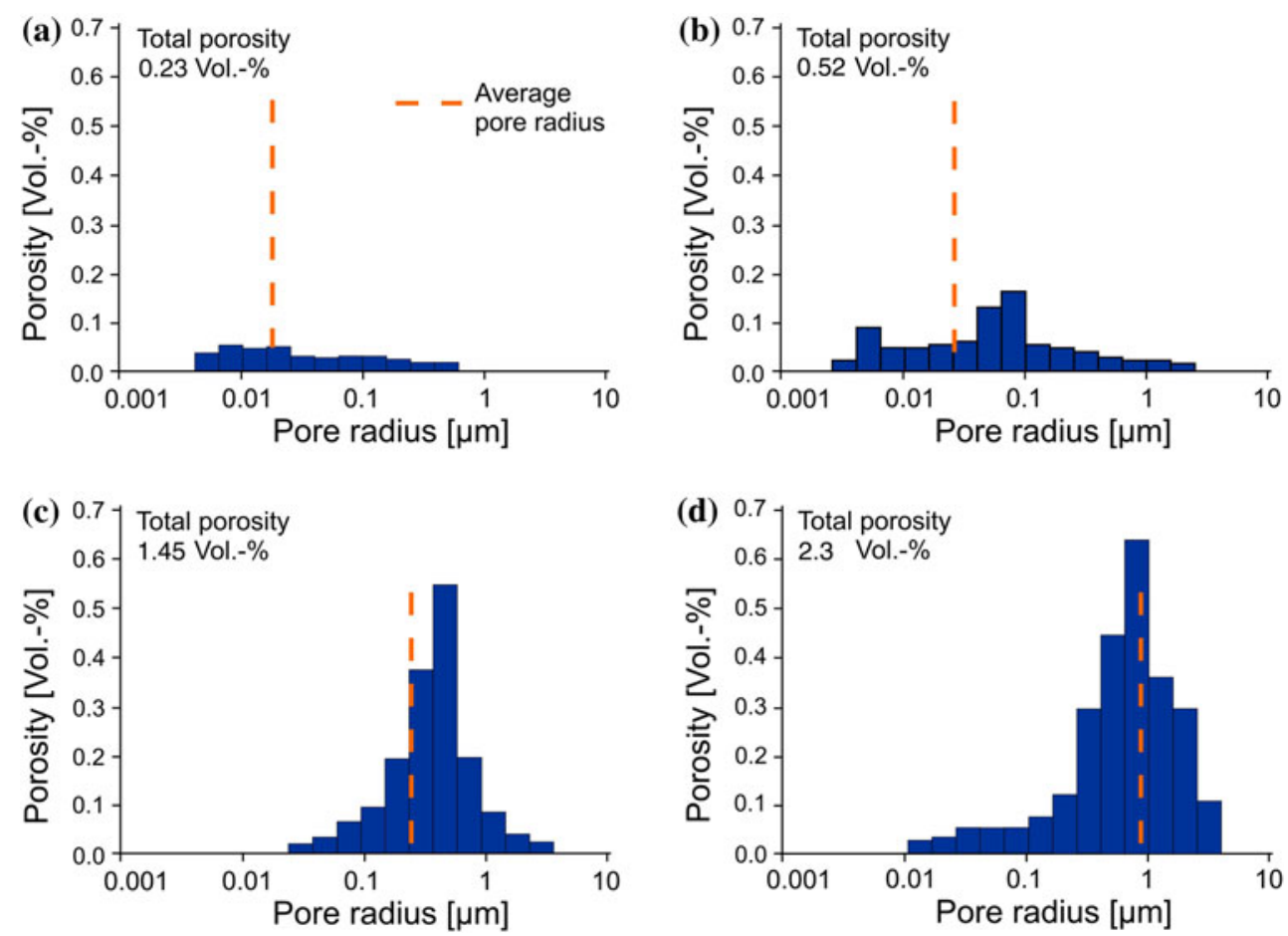

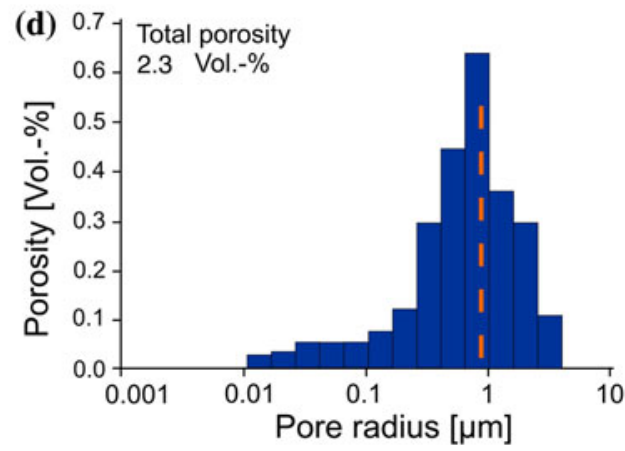

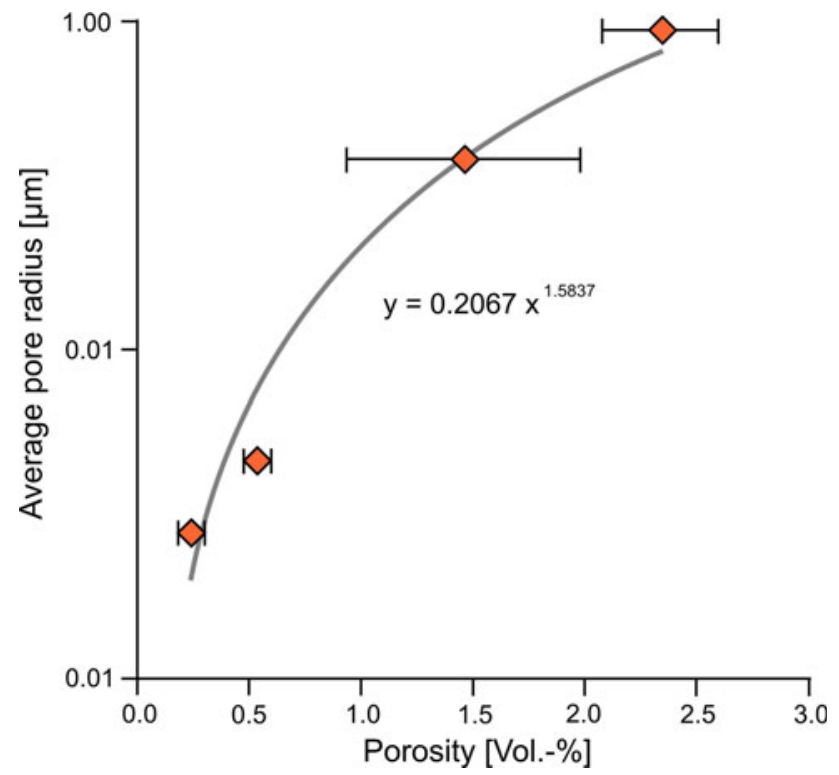

Fig. 8 Average pore radius versus porosity in the investigated samples

using compressional waves by means of a simple transmission procedure (Birch 1960, 1961). The compressional wave velocity $\left(V_{\mathrm{p}}\right)$ can be calculated by the time and distance travelled by the ultrasonic wave. A compressional wave oscillator operating at $250 \mathrm{kHz}$ utilizing a surface coupling device from the company Geotron was applied to measure the ultrasonic velocities. To compensate for any uneven surfaces and to create a better sonic transmission, coupling clay is used. The measurements were made on all sample bodies used for strength measurements parallel to the direction of stress and bending tensile load, respectively. Ultrasonic velocities of marbles are strongly dependent on the moisture content of the rock. Thus, marbles in the dry state can show velocities of $3.0 \mathrm{~km} / \mathrm{s}$, while under water-saturated conditions velocities may reach ca. $6.0 \mathrm{~km} / \mathrm{s}$ (Ruedrich et al. 2001a; Weiss et al. 2002a). The samples were therefore stored for at least 4 days at a temperature of $30{ }^{\circ} \mathrm{C}$ and a relative humidity of $20 \%$. The strongly damaged sample Cst (used as a compressive strength test body) showed compressional wave velocity values of around $1.6 \mathrm{~km} / \mathrm{s}$ (Table 3, 4; Fig. 10). The medium to strongly damaged sample Cme exhibits values between 2.5 and $2.8 \mathrm{~km} / \mathrm{s}$. Moreover, the velocities for samples Csl and Cfr lie between 3.4 and $5.6 \mathrm{~km} / \mathrm{s}$. The investigated samples cover the spectrum of ultrasonic velocities that are usually considered for marbles, and may also be measured in situ on marble objects (e.g. Köhler 1991; Ruedrich et al. 2001c; Snethlage et al. 1999; Siegesmund et al. 2007).

\section{Discussion}

For thousands of years marbles have been considered as a very unique natural building stone used in ancient/historical monuments. Marbles belong to one of the more significant rock groups with a total exploitation volume of ca. 20-30\%. Along with the aesthetic aspects the strength properties form the decisive criteria with respect to quality, 
Table 3 Strength and Young's modulus values as well as their associated ultrasonic velocities

\begin{tabular}{|c|c|c|c|c|c|c|c|c|c|c|}
\hline \multirow[t]{2}{*}{ Sample } & \multicolumn{2}{|c|}{$V_{\mathrm{p}}$ of $\sigma_{\mathrm{UCS}}$ samples $(\mathrm{km} / \mathrm{s})$} & \multicolumn{2}{|c|}{$\sigma_{\mathrm{UCS}}\left(\mathrm{N} / \mathrm{mm}^{2}\right)$} & \multicolumn{2}{|c|}{ E-modulus $\left(\mathrm{kN} \mathrm{mm}^{2}\right)$} & \multicolumn{2}{|c|}{$V_{\mathrm{p}}$ of $\sigma_{\mathrm{FS}}$ samples $(\mathrm{km} / \mathrm{s})$} & \multicolumn{2}{|c|}{$\sigma_{\mathrm{FS}}\left(\mathrm{N} / \mathrm{mm}^{2}\right)$} \\
\hline & Average & Deviation & Average & Deviation & Average & Deviation & Average & Deviation & Average & Deviation \\
\hline $\mathrm{Cfr}_{\|} \mathrm{X}$ & 5.51 & 0.13 & 104.52 & 4.46 & 30.84 & 5.83 & 6.09 & 0.06 & 18.35 & 1.25 \\
\hline $\mathrm{Cfr}_{\|} \mathrm{Z}$ & 5.57 & 0.14 & 103.79 & 1.31 & 35.67 & 1.10 & 6.21 & 0.09 & 20.22 & 3.26 \\
\hline $\mathrm{Csl}_{\| \mathrm{X}}$ & 3.48 & 0.06 & 100.79 & 12.81 & 20.12 & 9.85 & 4.34 & 0.08 & 12.15 & 0.84 \\
\hline $\mathrm{Csl}_{\|} \mathrm{Z}$ & 3.93 & 0.33 & 105.62 & 2.19 & 23.78 & 3.14 & 4.24 & 0.08 & 13.05 & 0.17 \\
\hline Cme $\| X$ & 2.54 & 0.27 & 79.02 & 5.51 & 17.20 & 1.85 & 2.63 & 0.11 & 6.92 & 0.69 \\
\hline $\mathrm{Cme}_{\|} \mathrm{Z}$ & 2.81 & 0.24 & 90.07 & 3.98 & 23.05 & 3.66 & 2.40 & 0.24 & 6.18 & 0.91 \\
\hline Cst $\| X$ & 1.56 & 0.12 & 40.89 & 7.27 & 7.37 & 2.14 & 2.06 & 0.21 & 1.33 & 0.72 \\
\hline Cst $\| \mathrm{Z}$ & 1.61 & 0.35 & 47.00 & 12.00 & 9.48 & 3.70 & 1.71 & 0.08 & 1.53 & 0.34 \\
\hline
\end{tabular}

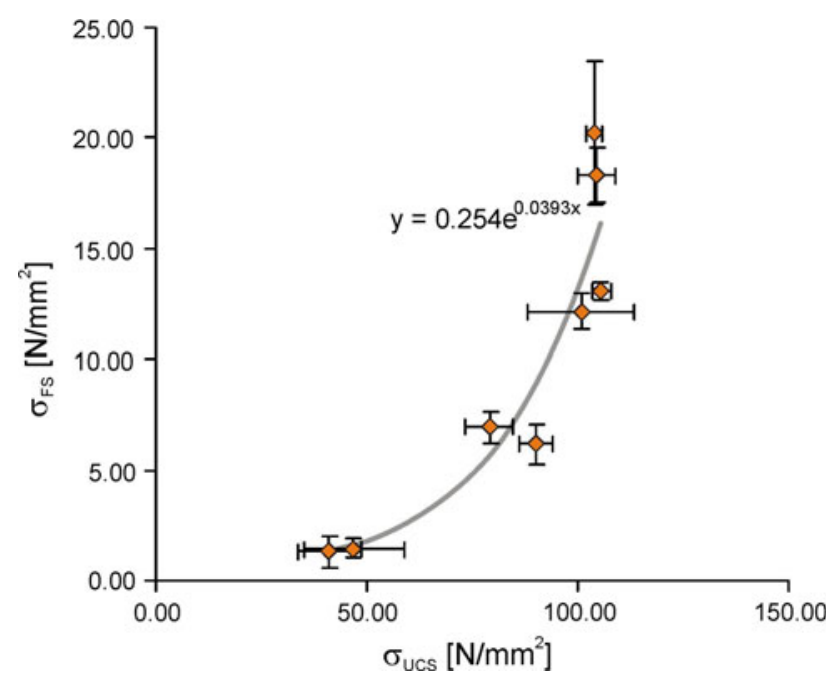

Fig. 9 Uniaxial compressive strength versus flexural strength of the investigated samples

the processing possibilities, and the application properties. From the physical properties of natural stones as well as their complexity, all of the crucial technical properties can be extrapolated for the use of this natural resource. Mineral composition and fabric determine the wide spectrum of the physical/technical properties, and in addition the degree of weathering, which is an important factor in the characterization of natural stones. Marbles have a very simple mineralogical composition, and surprisingly show distinct differences in weathering behavior. This is mainly due to the extraordinary physical properties of calcite crystals (the major rock-forming mineral of marbles) and the rock fabric of marbles. In the case of dolomitic marbles the weathering is less pronounced compared to calcitic marbles. Total fabric disintegration in marbles is a topic much discussed today, which in extreme cases leads to granular disintegration described as sugaring. This not only threatens important sculptures exposed outdoors, but is also a great danger on numerous buildings where marble is used as cladding. The prediction and interpretation of the quantitative damage plays an important role in this situation.

Weathering and its effect on the mechanical properties

The analysis of the mechanical properties is one of the tests often used on natural stones. Many tests, however, are destructive and are not applicable for solving the numerous problems in the field of monument preservation. The compressive strength is apparently in a constant relationship of $1: 10$ to $1: 15$ to the tensile strength (Hirschwald 1912). Flexural strength, on the other hand, attains a value of 2 to 2.5 times the value of the tensile strength. Based on statistical analyses, including around 2,100 commercial stones, Mosch and Siegesmund (2007) found that the compressive strength for marbles shows a variation ranging from 32.7 to $210.0 \mathrm{MPa}$, flexural strength from 2.7 to 28.0 MPa, and the tensile strength ranging from 2.4 to 24.4 MPa. On the basis of data presented in the literature, the determined strength results show a large scattering (Table 3). Furthermore, even the anisotropy is contained in the so-called scattering, which in marbles is very significant. From the statistical data it is also evident that the relationship discussed by Hirschwald (1912) is not met for marbles. For this rock group a significant different relationship is clearly evident (see Fig. 11).

The relatively low strength is directly related to the nearly monomineralic character of various marbles, as well as to the fabric inventory and the grain size distribution (Brosch et al. 2000; Zeisig et al. 2002). Different marble types are characterized by an equigranular and polygonal grain fabric (Weiss et al. 2002b; Shushakova et al. 2011). The decrease of the grain surface by the process of grain boundary area reduction leads to an almost complete equilibration of the grain boundaries. Consequently, the strength in such marble varieties can be significantly reduced, in contrast to such stones with stronger interlocking interlobate grain boundaries (Shushakova et al. 2011). Other authors have also shown that unweathered 
Table 4 Selected marble samples and their $V_{\mathrm{p}}$ data measured under dry and weathered conditions and also as a function of the state of weathering

\begin{tabular}{|c|c|c|c|c|c|c|c|c|}
\hline \multirow[t]{2}{*}{ Marble type } & \multirow[t]{2}{*}{ Sample condition } & \multirow[t]{2}{*}{ Porosity (vol. \%) } & \multicolumn{3}{|l|}{ Dry condition } & \multicolumn{3}{|c|}{ Water-saturated } \\
\hline & & & $V_{\text {pmax }}(\mathrm{km} / \mathrm{s})$ & $V_{\mathrm{pmin}}(\mathrm{km} / \mathrm{s})$ & Avp \%) & $V_{\text {pmax }}(\mathrm{km} / \mathrm{s})$ & $V_{\text {pmin }}(\mathrm{km} / \mathrm{s})$ & $\operatorname{Avp}(\%)$ \\
\hline \multirow[t]{3}{*}{ Carrara } & Fresh & 0.20 & 6.42 & 6.16 & 4.1 & 6.67 & 6.62 & 2.1 \\
\hline & Weathered & 0.43 & 4.50 & 4.07 & 9.5 & 6.06 & 5.92 & 2.9 \\
\hline & Strongly weathered & 2.12 & 2.44 & 1.63 & 33.0 & 4.83 & 4.67 & 3.3 \\
\hline Prieborn & Weathered & 0.55 & 3.97 & 2.93 & 26.1 & 6.16 & 5.74 & 6.8 \\
\hline \multirow[t]{2}{*}{ Kauffung } & Fresh & 0.23 & 6.58 & 5.43 & 17.8 & 7.17 & 6.31 & 12.0 \\
\hline & Weathered & 0.37 & 6.14 & 5.48 & 12.8 & 6.68 & 6.01 & 10.1 \\
\hline \multirow[t]{2}{*}{ GrossKunzendorf } & Fresh & 0.31 & 5.05 & 4.37 & 13.6 & 6.83 & 6.48 & 5.2 \\
\hline & Weathered & 0.77 & 4.84 & 2.45 & 49.3 & 6.50 & 5.81 & 10.5 \\
\hline \multirow[t]{2}{*}{ Lasa } & Fresh & 0.33 & 5.68 & 5.03 & 11.5 & 6.53 & 6.29 & 3.6 \\
\hline & Weathered & 0.45 & 4.48 & 3.77 & 16.0 & 5.92 & 5.64 & 4.7 \\
\hline \multirow[t]{2}{*}{ Sterzing } & Fresh & 0.30 & 6.40 & 4.87 & 23.8 & 6.87 & 6.06 & 11.7 \\
\hline & Weathered & 0.49 & 5.00 & 4.44 & 11.1 & 6.49 & 6.21 & 4.3 \\
\hline
\end{tabular}

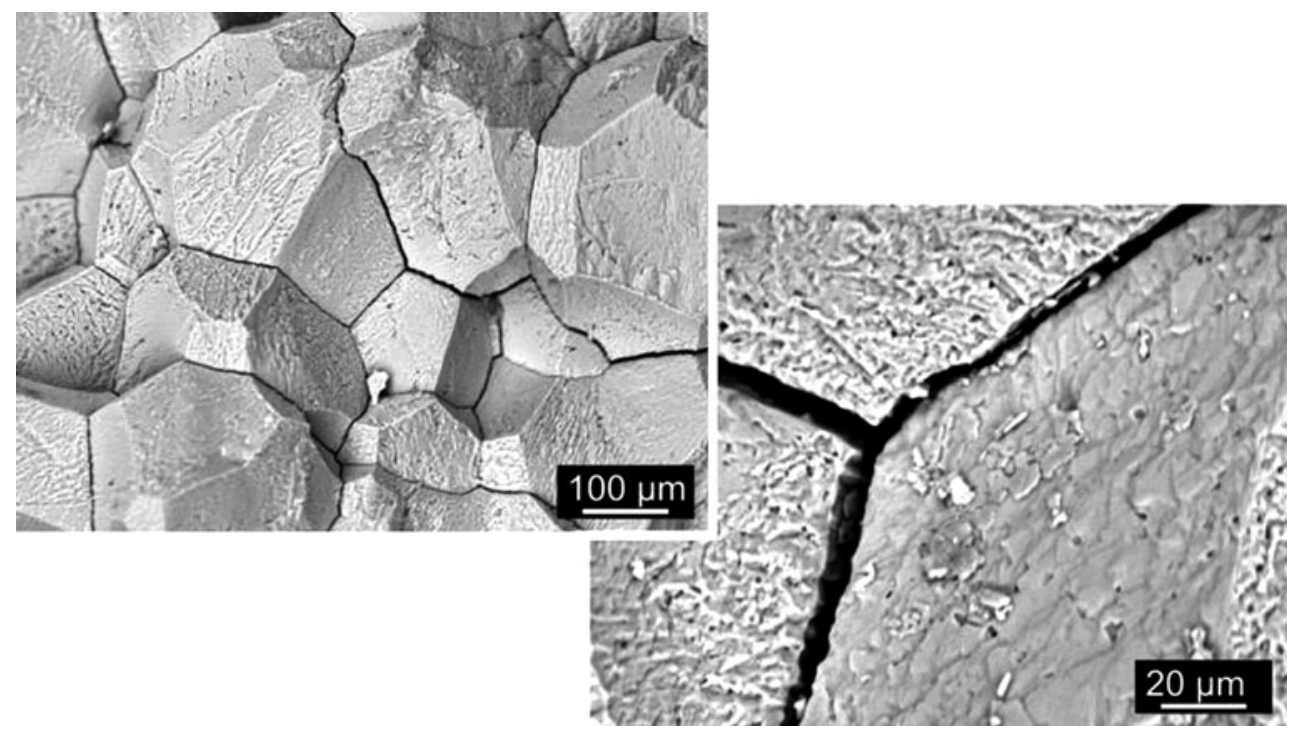

Fig. 10 SEM images depicting well-developed grain boundary fracturing or a loosening of grain boundary cohesion

marbles exhibit low tensile strengths when compared to other crystalline rocks (e.g. Fleischer 2002; Strohmeyer and Siegesmund 2002). Ruedrich (2003) investigated the fabric dependency of the tensile strength and its anisotropy on a Carrara marble. The analyses of the tensile strength were determined in 13 different directions, whereby the load in the Brazil test was turned in $15^{\circ}$ steps around the cylinder axis. Here the $90^{\circ}$ direction equates to the foliation plane. The minimum of the tensile strength for the Carrara marble was $3.4 \mathrm{MPa}$, whereas the maximum lies at 5.6 MPa. The anisotropy (A) reaches a value of $39 \%$. The fabric analysis has shown that during the tensile load the fracture zones are driven by a clear dependency on the grain fabric of the individual marble. Investigations on the fine-grained Carrara marble with its polygonal grain shapes and essentially straight grain boundaries show that the tensile cracks prefer to follow the grain boundaries and seldom trace an intracrystalline path (Siegesmund and Dürrast 2011, see Fig. 10).

The decrease in the marble strength following progressive weathering has been discussed in a number of publications (Ruedrich et al. 2001b; Koch and Siegesmund 2004; and Siegesmund et al. 2007). The flexural strength is reduced with increasing porosity, which is expressed as the amount of pore space and/or the crack volume in the total rock. This relationship almost takes the path of a potential function. This means that the weathering causes a new formation of the pore volume and is first connected to a 
Fig. 11 Correlation of strength data with the elastic properties
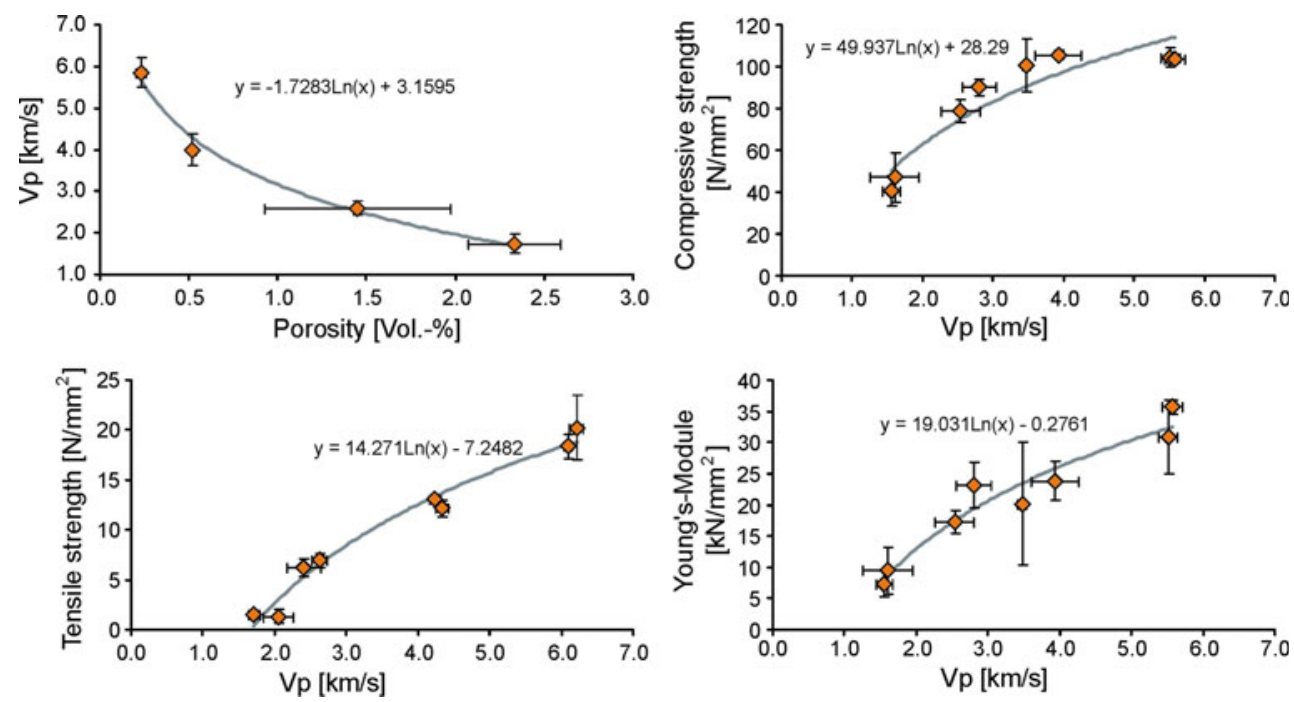

strong reduction in the rock strength, which slows down with every increase in the porosity. The formation of the crack volume in the rock also appears to be discernible in fresh or weakly weathered marble plates. The reduction in the flexural strength from ca. $20 \mathrm{MPa}$ down to $1.3 \mathrm{MPa}$ (Table 3) goes hand in hand with the destruction of the total fabric (Fig. 10). Values obtained for the static E-modulus calculated from the compressive strength display a majority trend, whereby those rocks with the highest strength also show the highest values for the E-modulus.

Weathering characterized by ultrasonic wave velocities

In many situations it is impossible to receive a large amount of samples for characterizing the state of the damaged marble objects. Therefore, in most cases the degree of weathering-caused disintegration on buildings and sculptures is determined by means of ultrasonic measurements. Here, the supposition is that the compressional wave velocity $\left(V_{\mathrm{p}}\right)$ can be directly correlated to the weathering condition. Based on measurements taken on objects constructed from different marble types (Carrara marble, Laaser marble, Silesian marble, see Ruedrich 2003), it could be shown that the evaluation of the petrophysical properties is not sufficient under the premise of a primary isotropic behavior (Siegesmund 1996; Siegesmund et al. 2007). From this it is evident that a simple $V_{\mathrm{p}} /$ porosity correlation is not sufficient without considering the composition, the pore space and its saturation and the rock fabric for characterizing the condition of weathering. The enormous decrease in the $V_{\mathrm{p}}$ can be explained by a decrease in the cohesion and accompanying reduction of the elastic coupling of calcite crystals in the marble fabric (see Fig. 10). By calculating the $V_{\mathrm{p}}$ value as a function of the porosity using the "time-average" equation after
Wyllie et al. (1956), which considers the pore space saturation and anisotropy, the calculated values lie much higher than the values measured by Köhler (1991). For a dry calcite marble (water saturation $\mathrm{S} w=0$ ) and a porosity of $2 \%$, a minimal value of $4.3 \mathrm{~km} \mathrm{~s}^{-1}$ can be calculated, which according to Köhler (1991) is opposite to the velocity of $2.4 \mathrm{~km} \mathrm{~s}^{-1}$. This example clearly shows that the observed decrease in the ultrasonic velocity with increasing weathering is primarily the result of the decoupling of the crystals and can not only be explained by a porosity increase.

Figures 4 and 11 clearly depict the Carrara samples, which exhibit different intensities of weathering, result from the $V_{\mathrm{p}}$ reduction due to the increase in porosity. When the calculated $V_{\mathrm{p}}$ velocities for the samples are plotted against the compressive strength, flexural strength and the Young's modulus, a decrease in the mechanical properties results from a reduction in the $V_{\mathrm{p}}$ (Fig. 11). Gebrande (1982) determined a mean density of $2.73 \mathrm{~g} / \mathrm{cm}^{3}$ based on 59 marble samples and a $V_{\mathrm{p}}$ velocity of $5.73 \mathrm{~km} / \mathrm{s}(80 \%$ confidence limits of $5.04-6.42 \mathrm{~km} / \mathrm{s}$ ) as well as a $V_{\mathrm{s}}$ velocity of $3.19 \mathrm{~km} / \mathrm{s} \quad(80 \%$ confidence limits of 2.71-3.66 km/s). This entails a Young's modulus of around $64 \mathrm{GPa}$.

For the diagnosis in the preservation of marbles by means of ultrasonic velocities, the question under consideration is what influence the porosity has on the velocity. Numerous models have been presented in the literature originating from different scientific disciplines, which correlate the ultrasonic velocities with the pore spaces in crystalline rocks (Fig. 12). Two different approaches will be tested against the data collected in this study. The comparison is done with the working hypothesis of Köhler (1991) and the model hypothesis from Weiss et al. (2001), which is based on the mathematical foundation of 
O'Connell and Budiansky (1974). The relationship of the $V_{\mathrm{p}}$ to porosity after Köhler (1991) is based on measurements conducted on the Carrara marble in various states of preservation. On the basis of these empirical data, Köhler developed a correlation function between the $V_{\mathrm{p}}$ and the porosity $\left(V_{\mathrm{p}}=\sqrt{ } 12 / \Phi\right)$.

Weathered marbles show lower ultrasonic velocities in the dry state than unweathered marbles. The decrease in the ultrasonic velocities results from the weathering generated microcrack growth (e.g. Weiss et al. 2001). The difference in the $V_{\mathrm{p}}$ properties between a crack-free sample and a sample with a high density of cracks represents the crackgenerated part in the ultrasonic characteristics (Rasolofosaon et al. 2000; Dürrast et al. 1999; Siegesmund et al. 2007). Numerous studies have discussed how far the velocity difference of the crack-generated ultrasonic velocity decrease can be evaluated as a measure for the damage in a marble (e.g. Köhler 1991; Weiss et al. 2001; Dürrast et al. 1999; Weiss et al. 2002a). Generally, the measured $V_{\mathrm{p}}$ velocities of ca. $7 \mathrm{~km} / \mathrm{s}$ for the unweathered state should be reduced almost to $1 \mathrm{~km} / \mathrm{s}$ for strongly weathered marbles (see Weiss et al. 2002b).

$V_{\mathrm{p}}$ values for different marbles are listed in Tables 3 and 4. The $V_{\mathrm{p}}$ spectrum varies between 1.63 and $6.14 \mathrm{~km} / \mathrm{s}$. This is similar to the spectrum of the Carrara marbles investigated here and shown in Fig. 12. With regard to the velocity anisotropies, variations between 9.5 and $49.3 \%$ could be determined.

According to the hypothetical model of Weiss et al. (2001), the velocity reduction can be understood as a function of the crack geometry. The underlying principle of the hypothesis is that the pre-existing porosity forms from certain types of ellipsoidal cracks. Thus, crack geometry is defined by a length relationship between the short axis and long axis (i.e. the aspect ratio). Circular pores would have an aspect ratio of 1 and flat pores would be less than 1 (see Fig. 12). The strong velocity reduction in weathered crystalline marbles can only be caused by very flat cracks (compare Weiss et al. 2001, 2002a, Fig. 12). Using 123 selected marble samples the $V_{\mathrm{p}}$ data were determined as a function of the porosity on a sample body (cubic-shaped) in the dry and water-saturated state (see also Ruedrich 2003 or Weiss et al. 2002b). In addition, the two hypothetical models have been added to the diagram (compare Weiss et al. 2001). In the dry state the samples show velocities ranging between 7.0 and $2.0 \mathrm{~km} /$ s. For most of the samples very low porosities were determined. Essentially these equate to the model approach of O'Connell and Budiansky (1974) in the predicted area of a strong ultrasonic decrease and a small porosity increase, which can only be caused by very flat cracks that have an aspect ratio of 0.005 .
Exceptions are represented by strongly weathered samples of Carrara and Grosskunzendorfer marble, which are found to have an aspect ratio of 0.01 . In microscale analysis both marbles show a modification of the crack geometry appearing in the form of corrosion (Fig. 13). This process leads to an increase in the porosity, but apparently does not have a pronounced effect on the ultrasonic velocities. For dry conditions it can be determined that the relationship of ultrasound to porosity also follows the empirical correlation function developed by Köhler (1991) as evident by the strong trend in the weathered Carrara sample. It can be assumed that marbles, which exhibit a purely mechanical crack formation, follow the model approach of O'Connel and Budiansky (1974), and thereby require a very small porosity increase with a strong velocity decrease. After a certain amount of disintegration, solution processes can become active that modify the microcracks and generate an opposite trend. Thus, a strong porosity increase correlates to a relatively small velocity reduction. When the samples are in the water-saturated state the trend of the experimental data is clearly flatter (see Fig. 12). The data for the Carrara marble deviate from the dry state with an aspect ratio of 0.005 . This lack of agreement is due to the fact that strongly weathered marbles in a water-saturated state show lower velocities than those in a crack-free condition. Therefore, these results do not agree with the model of O'Connel and Budiansky (1974).

The reduction of the ultrasonic velocities by progressive weathering of marbles is due to an increasing crack density and crack width. In addition, the type of cracks and their distribution are of crucial importance in rocks. According to microscale investigations, the respective cracks and the distribution pattern can be ascribed to specific fabric elements, although the grain fabric should be emphasized.

The coarse-grained marbles with interlocking grain boundaries show a completely deviating crack pattern as compared to the fine-grained polygonal grain fabric types. This is also reflected in the ultrasonic travel times. Furthermore, the intrinsic anisotropy generates a mostly directionally dependent ultrasonic velocity in marbles with a frequently pronounced texturing, which needs to be considered when characterizing the state of preservation.

The pore space is small but very efficient in reducing the velocities. All of the marbles exhibit water-saturated velocities within the range of 5.5 to $6.9 \mathrm{~km} \mathrm{~s}^{-1}$. The $V_{\text {pmax }}$ of the weathered Carrara marble is for example close to the $V_{\text {pmin }}$ of the fresh Carrara marble, and thus, these $0.4 \mathrm{~km} \mathrm{~s}^{-1}$ are within the accuracy of the measurement. Therefore, ultrasonic velocity measurements are extremely sensitive on type and degree of fluid saturation (see also Weiss et al. 2002a). 

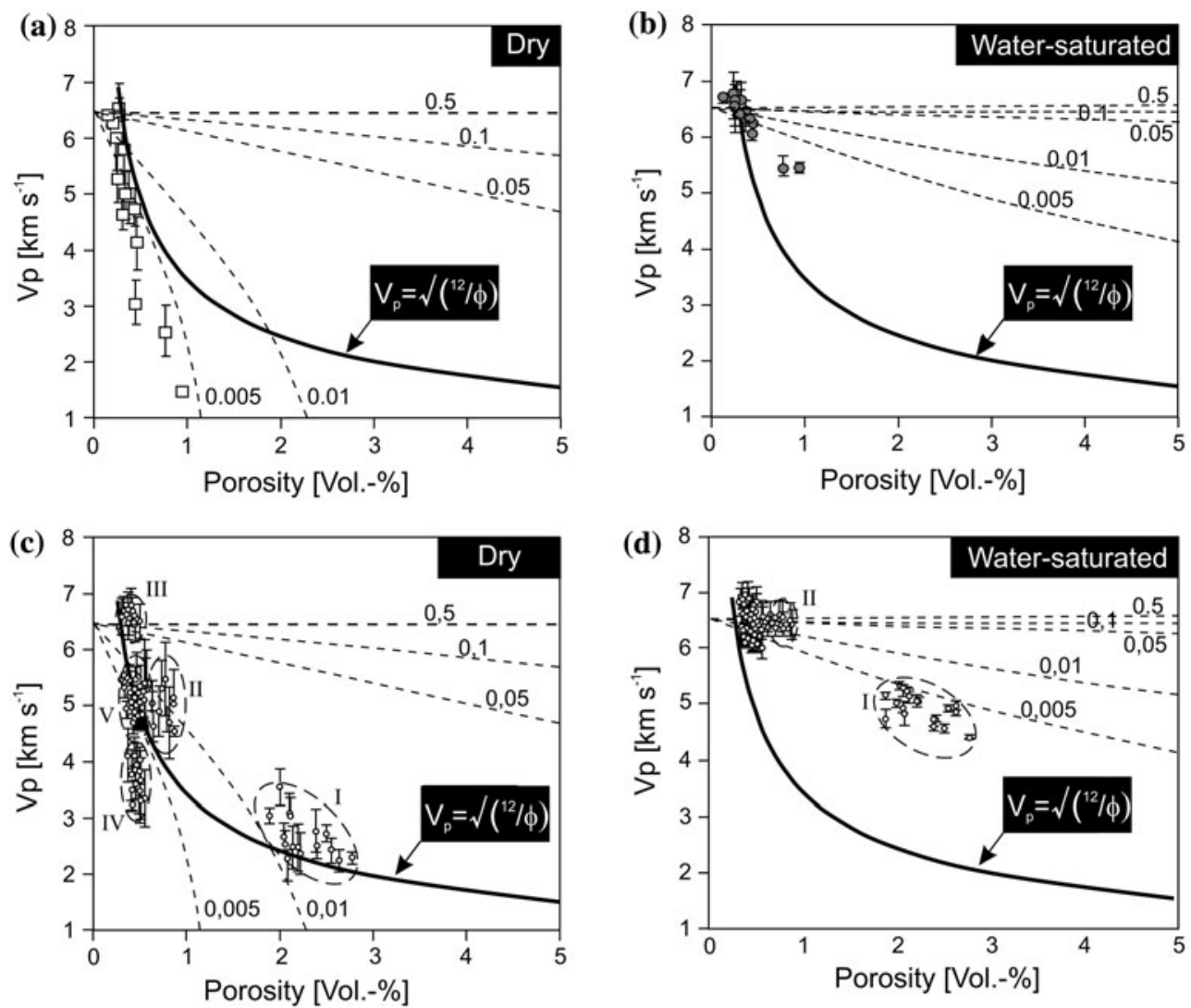

(e)

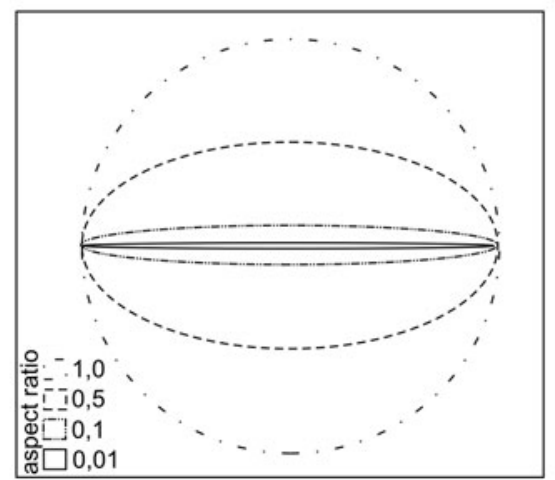

Fig. 12 Average compressional wave velocities for different marble samples as a function of porosity and sample condition: a dry samples and $\mathbf{b}$ water-saturated samples. The anisotropy of the respective marble is illustrated as error bars. The velocity/porosity curve of Köhler (1991; bold line) and the theoretical predictions according to the models of O'Connell and Budiansky (1974); (hatched lines) are added for comparison. For the latter model calculations, the aspect ratio of the cracks assumed in the computations are given. Moreover, in $\mathbf{c}$ and $\mathbf{d}$ the mean velocities of the compressive wave for various marble samples in dependence of the porosity and sample state are

\section{Stability assessment}

The Landesdenkmalamt Berlin (Perseveration Authority Berlin or Berlin Preservation Office) appointed a structural

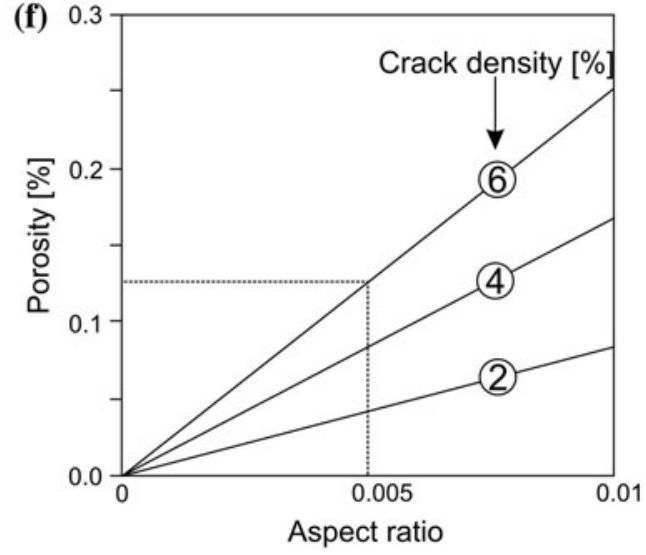

shown (I Carrara and II Grosskunzendorf, both strongly weathered; III Kauffung; $I V$ Prieborn; $V$ Lasa, Sterzing, Carrara, medium weathering condition). e Schematic representation of the aspect ratio for the sample geometry used in the modeling and based on O'Connel and Budiansky. By an aspect ratio of 0.01 the pores are extremely flat. f Theoretical calculation of the porosity increase due to thermal crack formation for different crack densities. A crack density of $6 \%$ (see dotted line) is realistic for thermally damaged marbles, which essentially gives an increase in the porosity of $0.125 \%$ (modified after Weiss et al. 2001, 2002b)

engineer to certify the structural safety of the statues based on the actual weathering state of the marble. These assessments where needed to guarantee the transportation safety on the bridge therefore, the flexural and compressive 


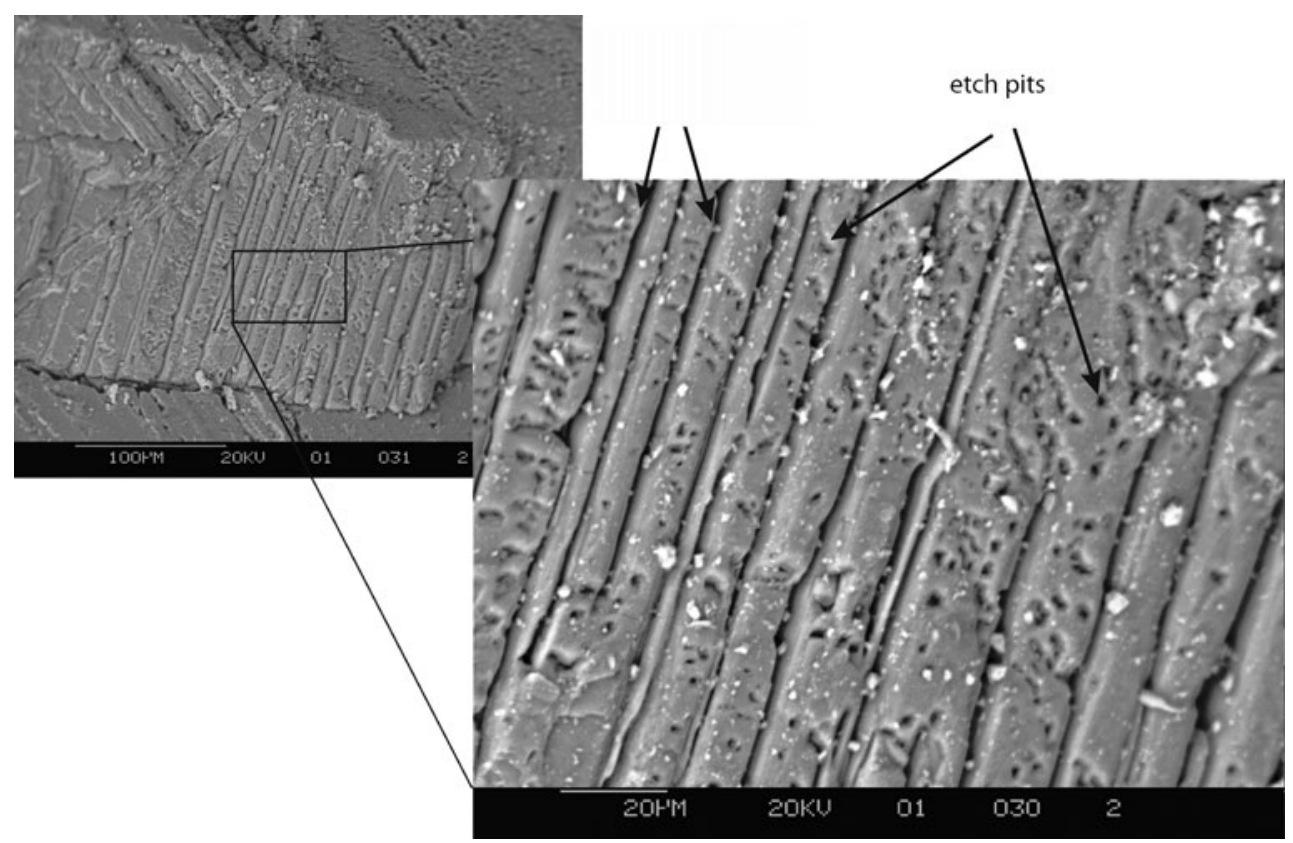

Fig. 13 Etch pits and corrosion phenomena in a marble sample under the SEM

Fig. 14 Intersection I-I near the footing of the statue showing the center of area $\mathrm{S}$

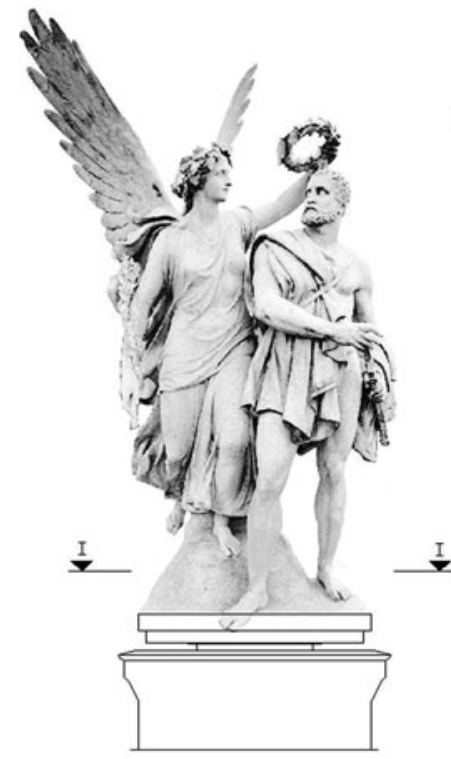

strengths of the statues were needed. These were estimated on the basis of the ultrasonic parameters for the leg area of the warrior and the Nike sculptures. The above-mentioned strength data and the corresponding velocity data on the weathered marbles are more or less comparable to the data observed on some sculptures from the Schlossbrücke, especially from the sculpture group "Nike Crowns the Hero". Sixty-four ultrasound velocities measured by Sobott (2008) show velocities up to $1.3 \mathrm{~km} / \mathrm{s}$ with an average value of around $2.2 \mathrm{~km} / \mathrm{s}$. These velocities and the

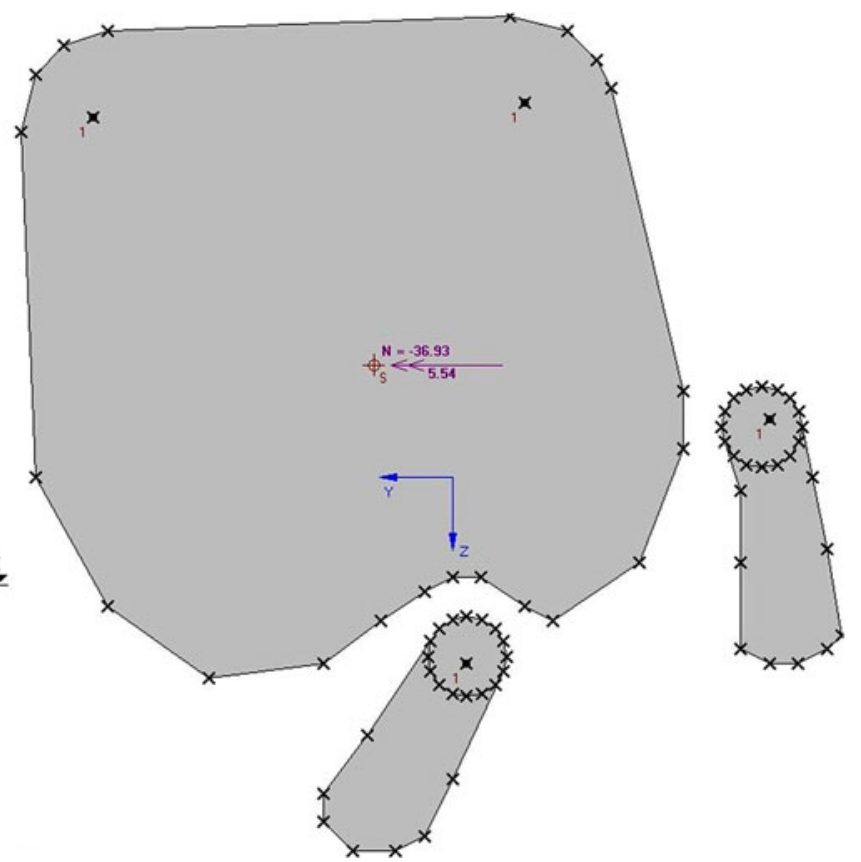

flexural and compressive strength data given in Fig. 11 are the basis for the internal stress calculation.

Based on a measurement of the main size proportions and photos of the statues, drawings of the outlines of the figures were generated (Figs. 14, 15). The overall dead load of the statue was estimated by scaling the average volume of a man with $70 \mathrm{~kg}$ weight which is $0.075 \mathrm{~m}^{3}$ by the size proportions. Using the density of the marble and the estimated volumes of the attachments of the figure the weight was calculated. The calculations indicate that the 
Fig. 15 Elevation of the figure group in the center of area $S$
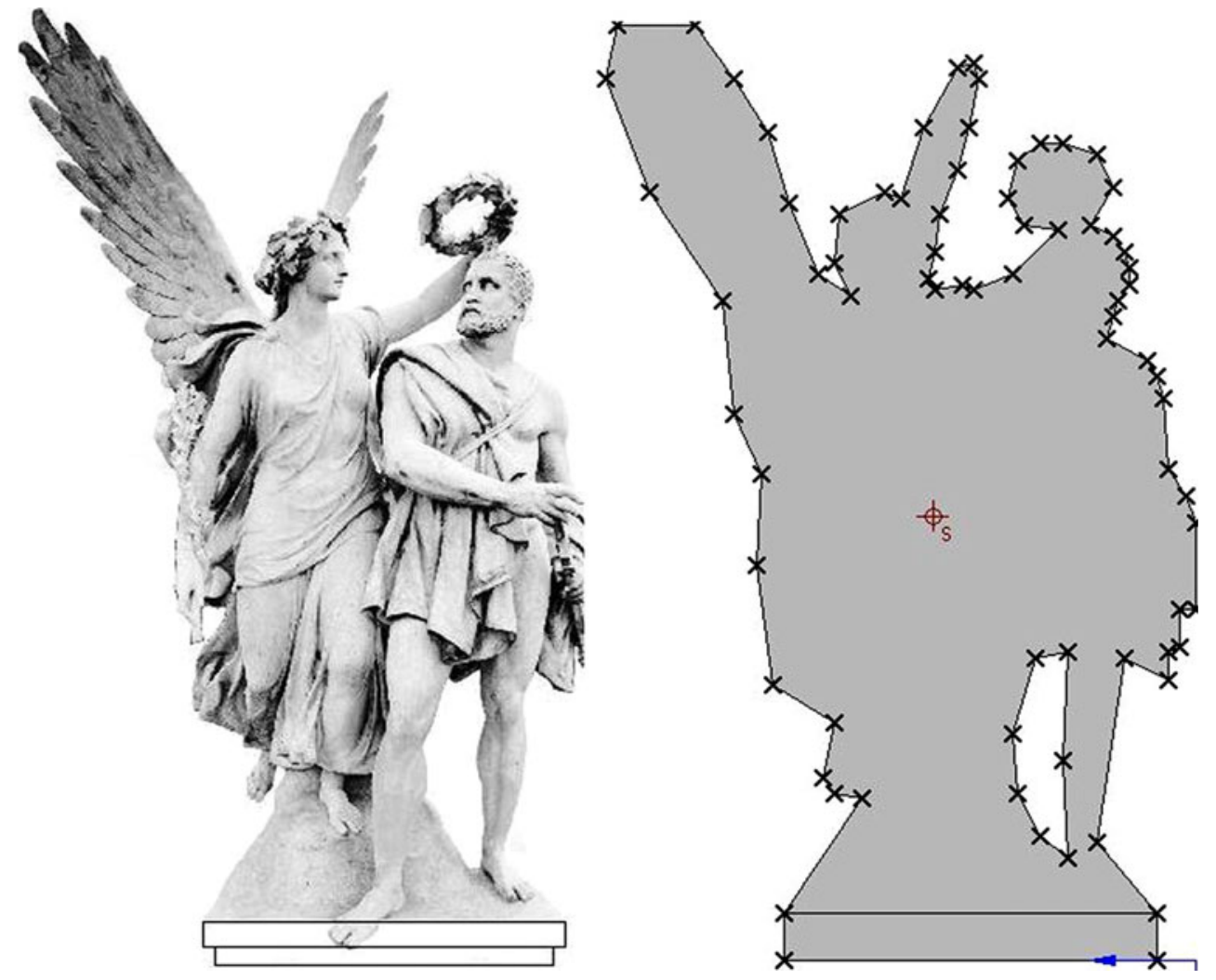

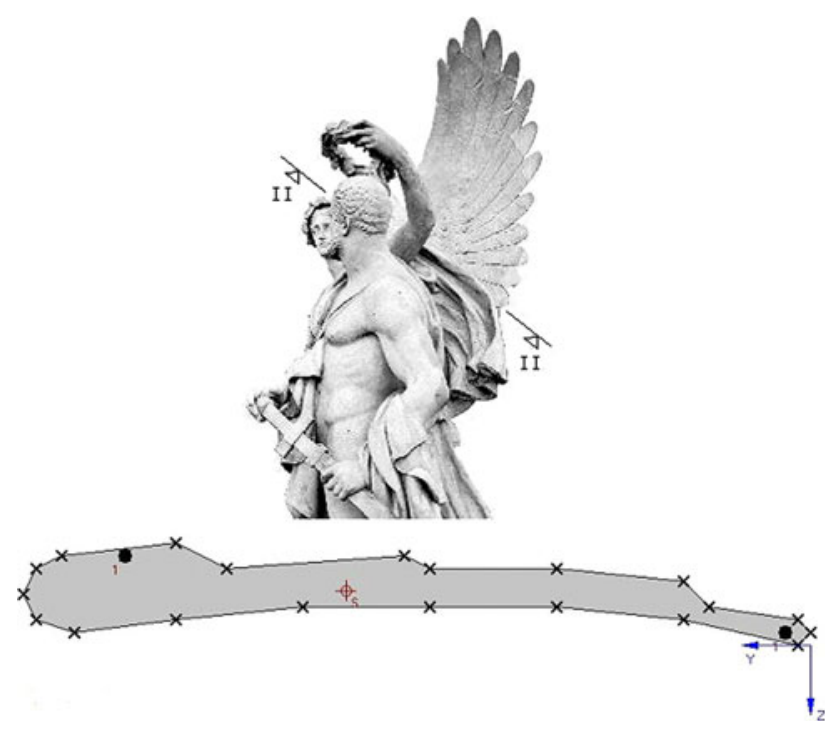

Fig. 16 Intersection of the wing of the statue

statuaries have a weight of 11.4 and $13.2 \mathrm{kN}$. Wind and snow pressures on the surfaces of the statues were estimated on the basis of German codes for wind and snow loads for a surrounding box of the figure group.

The main basis for the stability assessments of the whole statue group in addition to the assessments for individual parts of the statue is to calculate the main properties of areas in intersections and elevations of the statue. These are the center of the area, the moments of inertia and the main axes.

The safety factor for tilt based on the prior load and form estimations has been calculated to 1.28 , which is smaller than the factor of 1.5 required by the code regulations. Therefore, based on the result of the calculations the recommendation was that the statue should be anchored or heavy base plates should be attached to the statue.

In consequence, the internal stress calculations together with the P-wave velocities and the strength data reveal that the most critical parts like the wings of the sculpture and the crown holding hand must be replaced. These parts are designed and manufactured by sculptors for safety reasons.

Table 5 shows the results of the stress calculations. Near the joint of the wing to the figure (Fig. 16) the calculated internal stresses nearly reach the bending tensile strength of medium to strong weathered marble.

\section{Summary}

Although marble has a very simple mineralogical composition, i.e. calcite or dolomite as rock-forming minerals, the weathering features appear in a large variety of forms. In the case of the physical weathering of marbles, the phenomena may range from superficial disintegration to complete loss of cohesion along grain boundaries due to 
dilatancy, i.e. the total decay of the material. The decay of marbles is sometimes the most spectacular deterioration feature, although the loss in cohesion and the loss in strength are already evident without the well-known bowing of marble panels. Some of the mechanisms that have been suggested to explain the decay of marble include, marble type and its fabrics, stress relief, thermal expansion and expansion due to moisture and temperature (thermohygric properties) or the building physics and the chemical and or biological action.

The following conclusions can be drawn:

1. In contrast to the long period of stability in natural environments (time of marble formation up to the use as a building stone) marbles usually exhibit distinct weathering features up to complete decay after a comparatively short time of outside exposure on buildings. The rock fabric has a significant control on the material properties. The metamorphic and deformation history over the geological time span may lead to complex final rock fabrics (grain size, the configuration of grain boundaries, shape fabrics as well as lattice preferred orientation and microcracks).

2. For the Carrara marble a close relationship between quantified rock fabrics and the mechanical properties was also demonstrated as a function of an increasing state of weathering. In summary, the mechanical and physical properties decrease with weathering, while the porosity and the pore radii distribution increase.

3. Thermal and thermohydric dilatation processes are the main progressive decay processes of marbles. This leads to progressive crack initiation and propagation during weathering, while the pore space can be modified due to chemical and biological action.

4. The investigations have shown that marble decay causes a significant decrease in the strength properties (compressive strength, flexural strength, tensile strength, Young's modulus, etc.), while the porosity as well as the pore radii distribution changes. Combining the results from our study with the data in the literature, it becomes obvious that the usually accepted ratio between the compressive, flexural and tensile stresses is less pronounced than for other rock groups. The decrease of the mechanical properties with the increase in deterioration is significant but non-linear. Strength loss versus the increase in porosity relationship is representative for the investigated marbles.

5. Marbles usually show a strong directional dependence of strength properties. This anisotropy is clearly controlled by the marble fabric (i.e. differences in their microstructure as lattice preferred orientation, grain size, grain shape, grain shape
Table 5 Results of the stress calculations

\begin{tabular}{lll}
\hline & $\begin{array}{l}\text { Compression or bending } \\
\text { compression }\end{array}$ D $\left(\mathrm{N} / \mathrm{mm}^{2}\right)$ & $\begin{array}{l}\text { Tension or bending } \\
\text { tension }_{\mathrm{Z}}\left(\mathrm{N} / \mathrm{mm}^{2}\right)\end{array}$ \\
\hline $\begin{array}{c}\text { Ankle statue } \\
\text { "Sieger" }\end{array}$ & 0.71 & 0.016 \\
$\begin{array}{c}\text { Wing statue "Nike" } \\
\text { near joint to figure }\end{array}$ & 4.29 & 4.59 \\
\hline
\end{tabular}

fabrics, grain interlocking). The rock failure is not only controlled by the increasing porosity but also by the microstructure. The analyzed Carrara marble has a nearly equigranular-polygonal foam structure and shows significant grain boundary cracks. Since the respective grain fabric parameters control the directional dependence of the tensile strength, the preferred grain boundary orientation, texture, etc. are of significant importance. Also the weathering intensity must be taken into account for tensile strength measurements.

6. A conclusive result was obtained by combining the effect of strength loss and its relationship to the porosity and the compressional wave velocities. Several samples representing a broad variation in decay phenomena were used to constrain the loss in cohesion of this sample because the $V_{\mathrm{p}}$ velocities can be applied to characterize the Young's modulus of the marble, and thus, the derivation of the materials' quality or their heterogeneities, respectively.

7. $V_{\mathrm{p}}$ is also a measure for the decrease in strength. The reduction of the velocities with increasing state of weathering is correlated with an increasing microcrack density and microcrack width. In addition, the crack type and their distribution in the marble have a significant control on the velocity reduction. The microcrack formation is also crystallographically controlled, i.e. parallel to the cleavage planes or twins. The loading direction for example may control the initiation of intragranular cracks, while in other cases the shape fabric controls the opening of grain boundaries. Therefore, coarse-grained marbles with interlocking grain boundaries may show completely different microcrack patterns compared to finegrained marbles with polygonal grain boundaries. Consequently, the $V_{\mathrm{p}}$ velocities may differ significantly. If any lattice preferred orientation of the calcite and dolomite crystals exists, the directional dependence of the $V_{\mathrm{p}}$ velocities must be considered when discussing the state of weathering.

8. Ultrasonic wave velocity measurements are a powerful and sensitive tool for the damage assessment of marble. Experimental data reveal that the state of 
preservation of a marble is clearly documented by compressional wave velocities. For the maximum porosity of around $2.5 \%$, velocities determined on dry samples range on the order of $1.5 \mathrm{~km} / \mathrm{s}$. Modal calculations reveal that the velocity reduction is caused by cracks with an extreme aspect ratio of about 0.005 or even less.

9. If the microcracks are opened to certain extent, the chemical solution at internal surfaces may increase and lead to a strong increase in the porosity but only to a slight increase of the pore radii. This could explain the observed discrepancies between the experimentally determined and the modeled ultrasonic velocities.

10. Water saturation has an important influence on the magnitude and directional dependence of ultrasonic velocities. Hence, it is essential to gather sufficient information on the state of water saturation of an object made from marble to quantify the state of deterioration, since water as a pore fluid significantly increases the velocities. This observation is a key constrain when on-site inspections are performed.

11. Stability assessments are based on very low P-wave velocity data. The strength properties together with the internal stress calculations reveal that some mechanical critical parts must be replaced due to safety reasons. The analyses of the investigation and the statistical calculations lead the Heritage Preservation Office of Berlin to replace those parts on figure group 4 (wings and crowns) prone to progressive weathering with compliant sculptural material copies.

Acknowledgments Our work was supported by the Deutsche Bundesstiftung Umwelt and by the Heritage Preservation Authority in Berlin (Landesdenkmalamt Berlin). This paper was finalized by S.Siegesmund and is based on a draft by J. Ruedrich, who died during the work on this manuscript. With his passing we lost a very good friend and colleague and an excellent scientist.

Open Access This article is distributed under the terms of the Creative Commons Attribution License which permits any use, distribution, and reproduction in any medium, provided the original author(s) and the source are credited.

\section{References}

Birch F (1960) The velocity of compressional waves in rocks up to 10 kilobars. J Geophys Res 65:1083-1102

Birch F (1961) The velocity of compressional waves in rocks up to 10 kilobars; part 2. J Geophys Res 66:2199-2224

Brosch FJ, Schachner K, Blümel M, Fasching A, Fritz H (2000) Preliminary investigation results on fabrics and related physical properties of an anisotropic gneiss. J Struct Geol 22:1773-1787

Dürrast H, Siegesmund S, Prasad M (1999) Schadensanalyse von Natursteinen mittels Ultraschalldiagnostik: Möglichkeiten und Grenzen. Z d Deut Geol Ges 150(2):359-374
Duyster J (1991) Strukturtelle Untersuchungen im Moldanubikum (Waldviertel, Oesterreich) und methodische Untersuchungen zur bildanalytischen Gefügequantifizierung von Gneisen. PhD Thesis, University of Goettingen

Fleischer G (2002) Beurteilung von Ultraschalluntersuchungen an Natursteinobjekten in der Denkmalpflege. PhD thesis, Technische Universität Wien, p 184

Gebrande H (1982) Elastic wave velocities and constants of elasticity at normal conditions. In: Angenheister G (ed) Physical properties of rocks. Landolt-Börnstein Numerical Data and Functional Relationships in Science and Technology GroupV: Geophysics and Space Research, vol 1b. Springer, Berlin, pp 8-35

Hirschwald J (1912) Handbuch der bautechnischen Gesteinsprüfung. Verlag Gebrüder Bornträger, Berlin

Jornet A, Rück P (2000) Bowing of Carrara marble slabs: a case study. Proceedings of the International Congress "QuarryLaboratory-Monument". Pavia 2000:355-360

Koch A, Siegesmund S (2004) The combined effect of moisture and temperature on the anomalous expansion behaviour of marble. In: Siegesmund S, Viles H, Weiss T (eds) Stone Decay Hazards. Environmental Geology 46, pp 350-363

Köhler W (1988) Preservation problems of Carrara marble sculptures Potsdam-Sanssouci ("radical structural destruction" of Carrara marble). VI Internat. Congr. on Deterioration and Conservation of Stone, Proc Actes, pp 653-662

Köhler W (1991) Untersuchungen zu Verwitterungsvorgängen an Carrara-Marmor in Potsdam-Sanssouci.-Berichte zu Forschung und Praxis der Denkmalpflege in Deutschland, SteinschädenSteinkonservierung 2:50-53, Hannover

Leiss B, Ullemeyer K (1999) Texture characterisation of carbonate rocks and some implications for the modeling of physical anisotropies, derived from idealized texture types. In: Siegesmund S, Snethlage R, Vollbrecht A, Weiss T (eds) MarmorKonservierung. Z dt geol Ges, 150, Stuttgart, pp 259-274

Logan JM, Hadedt M, Lehnert D, Denton M (1993) A case study of the properties of marble as building veneer. Int J Rock Mech Min Sci Geomech 30:1531-1537

Mosch St., Siegesmund S (2007) Statistische Bewertung gesteintechnischer Kenndaten von Natursteinen. Z dt Ges Geowiss 158(4):821-868

O'Connell RJ, Budiansky B (1974) Seismic velocities in dry and saturated cracked solids. J Geophys Res 79(35):5412-5426

Passchier CW, Trouw RAJ (1996) Microtectonics. Springer, Berlin

Peck L, Barton CC, Gordon RB (1985) Microstructure and the resistance of rock to tensile fracture. J Geophys Res 90(13): 533-546

Rasolofosaon PNJ, Rabbel W, Siegesmund S, Vollbrecht A (2000) Characterization of crack distribution: fabric analysis versus ultrasonic inversion. Geophys J Int 141:413-424

Royer-Carfagni G (1999) On the thermal degradation of marble. Int J Rock Mech 36:119-126

Ruedrich J (2003) Gefügekontrollierte Verwitterung natürlicher und konservierter Marmore. Dissertation, Universität Göttingen, $158 \mathrm{~S}$

Ruedrich J, Weiss T, Siegesmund S (2001a) Deterioration characteristics of marbles from the Marmorpalais Potsdam. Z Deutsch Geol Ges 152:637-664

Ruedrich J, Siegesmund S, Richter D (2001b) Marble columns and its state of weathering: structural evidences and US-tomography. Z Deutsch Geol Ges 152:665-680

Ruedrich J, Weiss T, Siegesmund S (2001c) Deterioration characteristics of marbles from the Marmorpalais Potsdam (Germany): a compilation. Z dt Geol Ges 152:637-664

Shushakova V, Fuller ER Jr, Siegesmund S (2011) Influence of shape fabric and crystal texture on marble degradation phenomena: simulations. Environ Earth Sci 63(7-8):1587-1601 
Siegesmund S (1996) The significance of rock fabrics for the geological interpretation of geophysical anisotropies. Geotekt Forschungen 85:1-123

Siegesmund S, Dürrast H (2011) Mechanical and physical properties of rocks In: Siegesmund S, Snethlage $\mathrm{R}$ (eds) Stone in architecture, Springer, Berlin, pp 97-225. doi:10.1007/978-3642-14475-2_3

Siegesmund S, Weiss T, Vollbrecht A, Ullemeyer K (1999) Marble as a natural building stone: rock fabrics, physical and mechanical properties. In: Siegesmund S, Snethlage R, Vollbrecht A, Weiss $\mathrm{T}$ (eds) Marmor-Konservierung. Z dt geol Ges 150, Stuttgart, pp 237-258

Siegesmund S, Koch A, Ruedrich J (2007) Ursachen mangelnder Formbeständigkeit von Fassadenplatten: Fallstudie Universitätsbibliothek der Universität Göttingen. In: Siegesmund S, Ehling A (eds) Rohstoff Naturstein Teil 1, Z dt Ges Geowiss 158, Stuttgart, pp 630-648

Snethlage R, Ettl H, Sattler L (1999) Ultraschallmessungen an PMMA-getränkten Marmorskulpturen. Z Dt Geol Ges 150: 387-396

Sobott R (2008) Untersuchungen an den Figurengruppen No. 3 und 4 auf der Südseite der Berliner Schlossbrücke hinsichtlich des Festigkeitszustandes und früherer Konservierungen Bericht No. 3/08. Unpublished report, p 60

Strohmeyer D, Siegesmund S (2002) Influence of anisotropic fabric properties on the mechanical strength of selected building stones. Geol Soc Spec Publ 205:114-135

Ullemeyer K, Braun G, Dahms M, Kruhl J, Olesen N, Siegesmund S (2000) Current methods of texture analysis: application to a muscovite-bearing quartzite. J Struct Geol 22:1541-1557 van Brakel J, Modry S, Svata M (1981) Mercury porosimetry: state of the art. Powder Technol 29:1-12

Weiss T, Leiss B, Oppermann H, Siegesmund S (1999) Microfabric of fresh and weathered marbles: implications and consequences for the reconstruction of the Marmorpalais Potsdam. In: Siegesmund S, Snethlage R, Vollbrecht A, Weiss T (eds) MarmorKonservierung. Z dt geol Ges 150, Stuttgart, pp 313-332

Weiss T, Rasolofosaon PNJ, Siegesmund S (2001) Thermal microcracking in Carrara marble. Z dt Geol Ges 152:621-636

Weiss T, Rasolofosaon PNJ, Siegesmund S (2002) Ultrasonic wave velocities as a diagnostic tool for the quality assessment of marble). In: Siegesmund S, Weiss T, Vollbrecht A (eds) Natural stones, weathering phenomena, conservation strategies and case studies. Geological Society Special Publications 205, London, pp 149-164

Weiss T, Siegesmund S, Fuller E.R. (2002) Thermal stresses and microcracking in calcite and dolomite marbles via finite element modelling.). In: Siegesmund S, Weiss T, Vollbrecht A (eds) Natural Stones, Weathering Phenomena, Conservation Strategies and Case Studies. Geological Society Special Publications 205, London, pp 89-102

Wyllie MRJ, Gregory AR, Gardner LW (1956) Elastic wave velocities in heterogeneous and porous media. Geophysics 21:41-70

Zeisig A, Siegesmund S, Weiss T (2002) Thermal expansion and its control on the durability of marbles. In: Siegesmund S, Weiss T, Vollbrecht A (eds) Natural Stones, Weathering Phenomena, Conservation Strategies and Case Studies. Geological Society Special Publications 205, London, pp 65-80 